Portland State University

PDXScholar

\title{
Deoxyribonucleic Acid and Other Words Students Avoid Speaking Aloud: Evaluating the Role of Pronunciation on Participation in Secondary School Science Classroom Conversations
}

Stacie Elizabeth Beck

Portland State University

Follow this and additional works at: https://pdxscholar.library.pdx.edu/open_access_etds

Part of the Science and Mathematics Education Commons, and the Secondary Education and Teaching Commons

Let us know how access to this document benefits you.

\section{Recommended Citation}

Beck, Stacie Elizabeth, "Deoxyribonucleic Acid and Other Words Students Avoid Speaking Aloud: Evaluating the Role of Pronunciation on Participation in Secondary School Science Classroom Conversations" (2013). Dissertations and Theses. Paper 1088.

https://doi.org/10.15760/etd.1088

This Thesis is brought to you for free and open access. It has been accepted for inclusion in Dissertations and Theses by an authorized administrator of PDXScholar. Please contact us if we can make this document more accessible: pdxscholar@pdx.edu. 
Deoxyribonucleic Acid and Other Words Students Avoid Speaking Aloud:

Evaluating the Role of Pronunciation on Participation in Secondary School Science

Classroom Conversations

by

Stacie Elizabeth Beck

A thesis submitted in partial fulfillment of the requirements for the degree of

Master of Science in Teaching

in

General Science

Thesis Committee:

Michael Flower, Chair

Cary Sneider

Melissa Potter

Brooke Mayo

Portland State University

2013 


\begin{abstract}
Student's verbal participation in science classrooms is an essential element in building the skills necessary for proficiency in scientific literacy and discourse. The myriad of new, multisyllabic vocabulary terms introduced in one year of secondary school biology instruction can overwhelm students and further impede the self-efficacy needed for concise constructions of scientific explanations and arguments. Factors inhibiting students' inclination to answer questions, share ideas and respond to peers in biology classrooms include confidence and self-perceived competence in appropriately speaking the language of science. Providing students with explicit, engaging instruction in methods to develop vocabulary for use in expressing conclusions is critical for expanding comprehension of science concepts.

This study fused the recommended strategies for engaging vocabulary instruction with linguistic practices for teaching pronunciation to examine the relationship between a student's ability to pronounce challenging bio-terminology and their propensity to speak in teacher-led, guided classroom discussions. Interviews, surveys, and measurements quantifying and qualifying students' participation in class discussions before and after explicit instruction in pronunciation were used to evaluate the potential of this strategy as an appropriate tool for increasing students' self-efficacy and willingness to engage in biology classroom conversations. The findings of this study showed a significant increase in student verbal participation in classroom discussions after explicit instruction in pronunciation combined with vocabulary literacy strategies. This research also showed an increase in the use of vocabulary words in student comments after the intervention.
\end{abstract}




\section{TABLE OF CONTENTS}

Abstract

List of Tables $\quad$ iv

List of Figures $\quad$ V

Chapter 1: Introduction 1

$\begin{array}{ll}\text { Chapter 2: Literature Review } & 7\end{array}$

Vocabulary Knowledge and Student Achievement 7

Vocabulary Knowledge and Student Achievement: Instructional Methods 10

Oral Communication Skills and Scientific Literacy 13

Impediments and Enhancers in Oral Communication 18

$\begin{array}{ll}\text { Summary } & 21\end{array}$

Chapter 3: Method 23

Method Overview 23

$\begin{array}{ll}\text { Participants } & 25\end{array}$

$\begin{array}{ll}\text { Treatment } & 25\end{array}$

Lesson 1: An Introduction to Linguistics and Vocabulary Flashcards. 27

Lesson 2: Read-Alouds.

Lesson 3: Science Words and Storytelling. 31

Lesson 4: Terminology with Technology. 31

Lesson 5: Reverse Jeopardy.

Instruments 33

Frequency of Student Participation and Use of Scientific Vocabulary: 34

Survey of Student Self-Efficacy in Scientific Discourse: 35

Student Interviews: $\quad 36$

$\begin{array}{ll}\text { Procedure } & 37\end{array}$ 
Chapter 4: Results $\quad 40$

Gains in Verbal Participation 40

Gains in the Verbal Use of Scientific Vocabulary 43

Correlations between Student Participation Gains and Survey Responses 48

Interview Results

$\begin{array}{ll}\text { Chapter 5: Discussion } & 57\end{array}$

Interpretation of Findings $\quad 57$

$\begin{array}{ll}\text { Conclusion } & 60\end{array}$

Limitations $\quad 64$

$\begin{array}{ll}\text { Recommendations } & 67\end{array}$

References

Appendix A: Student Participation and Use of Scientific Vocabulary $\begin{array}{ll}\text { Data Collection Form } & 72\end{array}$

Appendix B: Survey of Student Self-Efficacy in Scientific Discourse 73

Appendix C: Vocabulary Terms

Appendix D: Application and Approval for Human Subjects 75 


\section{LIST OF TABLES}

Table 1: Experimental design.....

Table 2: Treatment lesson plans and corresponding instructional strategies from the

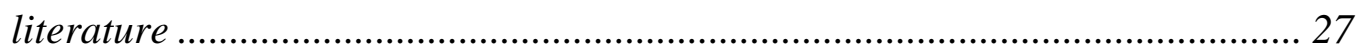

Table 3: Verbal participation mean, SD, and t-test results .......................................... 41

Table 4: Descriptive statistics for the frequency of student comment types .................... 44

Table 5: t-tests for statistical significance in mean frequency of student comments using

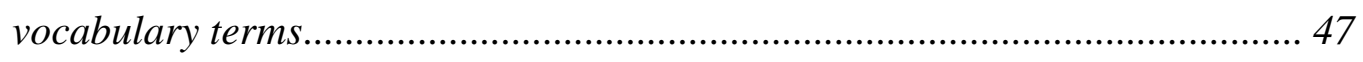

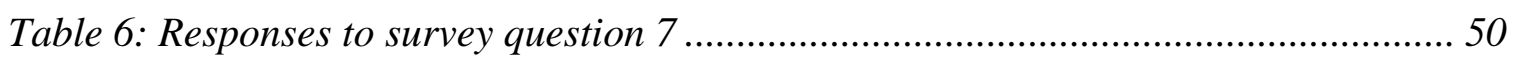

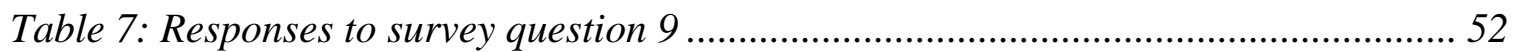

Table 8: Most and least helpful instructional strategies for learning scientific vocabulary, as reported by ..................................................................... 53 


\section{LIST OF FIGURES}

Figure 1: Adapted Frayer-model vocabulary flashcard with phonetic spelling -

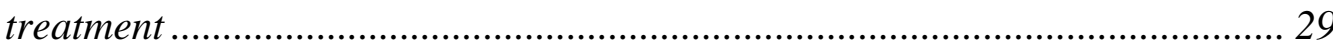

Figure 2: Adapted Frayer-model vocabulary flashcard without phonetic spelling -

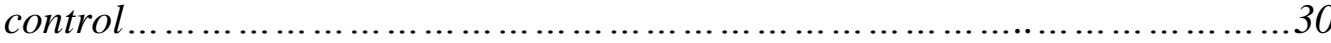

Figure 3: Histogram of mean pre-and post-treatment participation frequencies for Group A................................................................................................. 42

Figure 4: Histogram of mean pre-and post-treatment participation frequencies for

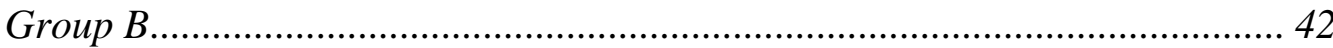

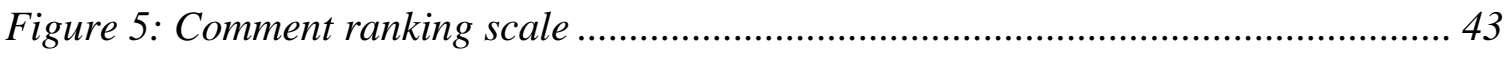

Figure 6: Histogram of the frequency of comment types pre-and post-intervention....... 46

Figure 7: Linear model with correlation coefficient for pre-and post-intervention verbal use of high-value vocabulary ................................................................... 48 


\section{CHAPTER 1: INTRODUCTION}

Introduction

As far as many of our secondary students are concerned, biology may very well be deemed "the study of exotic terminology" (Milligan \& Orlich, 1981). A high school biology textbook analysis by Groves (1995) found 1,899 terms intended for student memorization and comprehension. While current trends in science education are leading away from deluging students with abstruse terminology (Fisher, 2007; Carnine \& Carnine, 2004), vocabulary development remains an essential element needed to successfully communicate scientific information. Coinciding with the importance of vocabulary development is the indispensable ability to use those words in oral discourse about science phenomena and critical global concerns. Pronunciation of the technical vocabulary associated with biological sciences can impede to students' willingness to join these conversations. Use of the words essential to understanding the scientific process adds precision to thinking and communicating; without a clear grasp of this technical terminology students may substitute words which are less than helpful in discourse and comprehension or choose not to speak at all (Wilson, 1998). The purpose of this study was to evaluate the effects of explicit instruction in the pronunciation of bioterminology on students' participation in guided classroom conversations.

The development of scientific conversations in the classroom allows students to become socialized into the culture and discursive practices of science, yet there is still much to be learned about how educators can support the development of scientific conversations in the secondary school classroom (Alozie et al., 2009). Educators have an 
ample supply of teaching tools at their disposal to bring scientific discourse into their classrooms, but must choose the strategies most appropriate for their curriculum, grade level and students' cognitive abilities. Inquiry? Guided discussions of social implications of science? Socratic seminars? Debates? Few of these methods will lead to gains in proficiency if the essential skills and practices needed for scientific discourse are not first explicitly taught. A Framework for K-12 Science Education: Practices, Crosscutting Concepts, and Core Ideas (National Research Council, 2012), lists three of seven essential practices in science and engineering as: constructing explanations, engaging in argument from evidence, and obtaining, evaluating, and communicating information (p. 3). Instruction in the language of science requires that students first have the vocabulary of the field, the ability to construct valid explanations and the self-efficacy to use the two amongst their peers. Oral communication abilities are critical scientific literacy practices for participation in a global community where students will be expected to retrieve, critically evaluate, organize and analyze information, and to draw reasonable, evidencebased conclusions for making decisions relative to all aspects of life (Krajcik \& Sutherland, 2010; Spektor-Levy, Eylon \& Scherz, 2009). The skills and practices deemed necessary for scientific discourse begin to grow after constructing a solid foundation of relevant vocabulary.

Vocabulary instruction strategies have moved beyond passing out long lists of foreign-looking words and telling students to use the textbook glossary to record the definitions verbatim. Engaging vocabulary strategies have been proposed by Carnine \& Carnine (2004), Marzano (2004), and Young (2005). These teaching techniques each 
emphasize limiting words to those that are most fundamental to the content and transferable to other academic areas. Effective methods of vocabulary instruction for comprehension include providing students multiple opportunities to apply new words in relevant contexts, to develop their own understandings and to use the words aloud in relevant conversation. Speaking about material is itself an exercise in critical thinking (Curto \& Bayer, 2005) and allows comprehension to expand beyond the simplistic. Proficiency in the language of science can increase interest in science content and allow depth and insight into the relevance of this often daunting material (Miller, 2005). When the expected terminology becomes part of the classroom conversation, inquiry and insight may emerge and add to the language of any culture embracing it (Miller, 2005).

Many factors can inhibit students from actively participating in guided classroom discussion framed around complex concepts such as meiosis, heterozygous alleles or effects of Ancylostoma on the digestive tract, but the counterproductive, affective state of embarrassment should not be one of them. The perceived inability to pronounce multisyllabic vocabulary words, those that often dominate the language of science, can lead students to self-consciousness, tension, frustration (Murphy, 1991) and ultimately a lack of engagement in science content. In the post-secondary school professional world, stumbling over technical terminology can potentially lead to a loss of credibility amongst peers (Dunn 1989). Attaining better pronunciation habits can be linked to an increase in students' positive affective states, which encourages the practice of educators providing students opportunities to improve their linguistic accuracy (Murphy, 1991). 
Any educator who has ever had the experience of posing a question to a classroom full of attentive students and been answered by a resounding silence understands the importance of participation to a productive lesson. Numerous anecdotal experiences by this researcher have shown that students who believe they will be mocked by their peers for mispronunciation chose not to speak, even when they knew the correct response or had valuable input for the conversation. While there are a plethora of factors that may deter students from verbalizing their thoughts and sharing their understandings, the rationale of this study is that the role of self-efficacy in pronouncing perplexing biological vocabulary is an inhibiting factor science teachers can help their students overcome through explicit instruction. As a researcher of TESOL strategies, Murphy (1991) purports that a student's efficacy to pronounce and correctly use new words in context stems from structured stages of practice and instruction. This hierarchy resembles that of many general educational theorists, where knowledge and skills build upon prior knowledge and abilities; higher level thinking does not spontaneously occur. This research will incorporate the literacy strategies prudent to teaching scientific vocabulary in combination with the linguistic theories used in general language instruction as described by Murphy (1991).

Using a mixed method approach, this experimental study attempted to answer the question: can the frequency and propensity of student participation in class discussion be increased by instruction in the pronunciation of scientific vocabulary? This study suggested that by using interactive, applicable vocabulary instruction practices, accentuating the pronunciation of biological terminology, students who have had multiple 
opportunities to use these words aloud more frequently participated in guided class discussions and applied the content terminology to science-based conversations. The independent variable of the research, applied once with each sample group, was explicit instruction in pronunciation of bio-terminology. The dependent variable was a measurable change in student participation post-instruction compared to participation frequencies without pronunciation instruction. Phonetic accuracy in pronunciation was not the significant outcome for this study; acceptance of the hypothesis was based on the increased efforts put forth by students to engage in scientific discourse in the classroom.

To measure changes in the frequency of participation in guided class discussions pre- and post-intervention, numerical records of the quality and quantity of verbal outputs of each student was collected. Two classes of general high school biology students in the greater Portland, Oregon metro area comprised the sample, and each received one unit of pronunciation and engaged vocabulary instruction (the experimental treatment) and one unit of engaged vocabulary instruction only (the control treatment). The experimental instruction embedded Marzano's Six-Step Process for Teaching New Terms (2004) with Murphy's Scale of Activities for Accuracy in Oral Communication by Proficiency Level (1991). These two methods were chosen for their validity as effective strategies in developing scientific literacy and linguistic skills. Students' self-efficacy in communicating science words and concepts was evaluated with interviews and surveys to analyze the effectiveness and relevancy of pronunciation instruction from the student perspective. Questions about how educators can support the development of scientific discourse in the classroom have multi-layered answers and this research in pronunciation 
instruction attempted to yield one possible strategy that merges essential elements of scientific literacy and student self-efficacy: verbal communication aptitude and the propensity to participate. 


\section{CHAPTER 2: LiterATURE REVIEW}

\section{Literature Review}

To provide context for the current state of vocabulary instruction and oral communication in the science classroom, the following review of the literature summarizes studies that address vocabulary knowledge, oral language skills and student achievement. A further consideration of the relevant literature will provide a brief review of instructional methods associated with vocabulary and language literacy. The report concludes with a summary of studies evaluating the relationship between oral communication and scientific content knowledge. The final section summarizes papers on the skills suggested by researchers for students to become competent oral communicators.

\section{Vocabulary Knowledge and Student Achievement}

A recent quantitative analysis by Townsend et al. (2012) researched the relationship between academic word knowledge and academic achievement in a population of diverse middle school students. Measuring the breadth of overall vocabulary knowledge and general academic word knowledge, this research sought to determine if the quantity of student's vocabulary could be associated with standardized test scores in reading comprehension, math, social science and science. The participants in the study consisted of 339 seventh and eighth graders of diverse linguistic and socioeconomic backgrounds from an urban school district. All students in the sample took the multiple choice Vocabulary Subtest of the Gates-MacGinitie Reading Test 
designed to assess the overall range of their vocabulary knowledge across a variety of texts, not only academic materials. Students were also given the Academic Word Level Subtest of the Vocabulary Levels Test (VLT), determining general academic word knowledge (i.e. those words that occur in academic texts, but are cross-disciplinary such as function and structure). As a final measurement tool to assess academic achievement within content areas, students were administered the Iowa Basic Skills Test and the Criterion Referenced Test. The results of these standardized exams supported the authors' primary claim that the vocabulary and achievement gap between lowsocioeconomic/language minority students and their English-only/ standard socioeconomic status is prevalent and wide. Using regression models and multiple statistical analysis methods, the data collected on both overall vocabulary breadth and general academic word knowledge positively correlated to academic achievement across disciplines. The researchers concluded that the empirical evidence provided by this study should further support the need for content area teachers to explicitly instruct general academic vocabulary in addition to discipline specific terminology, as vocabulary knowledge in its entirety supports reading comprehension and student achievement. Fisher (2007) describes the qualitative inputs and quantitative outputs of student achievement after a four year, schoolwide vocabulary instruction initiative at the urban Hoover High School in San Diego, CA. Starting in 2001 with 200 ninth graders, GatesMacGinitie reading assessment scores were recorded at a school with the highest crime, poverty and teen pregnancy rates and lowest achievement rates in the state. These students scored at the 6.01 grade level and answered only $30 \%$ of vocabulary questions 
correctly on the state standards assessment. In an effort to increase achievement in vocabulary performance and consequently content area text comprehension, a five-part vocabulary instruction plan was implemented throughout the school and standardized test score data was tracked for a randomly selected group of ninth grade students. The five components of the initiative were: 1) a 20 minute per day silent sustained reading period for all students, teachers and staff in addition to independent reading time in subject area classes, focused on content matter; 2) 3-5 minute read-alouds by every teacher to every class; 3 ) content vocabulary instruction in the form of vocabulary role play, journals, word walls, semantic mapping and/or additional evidence-based teaching strategies, using key terms identified by the department; 4) academic vocabulary instruction using Academic Word Lists to focus on common words with multiple meanings that were found to hinder students' understanding; and 5) Words of the Week, consisting of five words with an identical prefix, suffix or root, were posted in every classroom, electronic marquis, the school bulletin and incorporated in raps performed by students in a public area each week. In 2005, the remaining 143 students from the original sample were again given the Gates-MacGinitie reading assessment test and averaged 9.94, an average of 0.98 years growth per year of attendance, compared to an average of 0.67 years growth in grades K-8. Fisher also analyzed state standards assessment data across the entire school and found a $17 \%$ increase in reading comprehension scores and a $25 \%$ increase in vocabulary scores. Content area scores, as measured by the Academic Performance Index, increased from 444 to 580 points over the four-year vocabulary instruction program. Fisher concludes that this schoolwide vocabulary initiative can improve 
student's reading assessments, content area comprehension and state achievement test scores, but recommends that all stakeholders, including teachers, administrators, and support staff are involved in the design, development and implementation of such a program (p. 349).

\section{Vocabulary Knowledge and Student Achievement: Instructional Methods}

A meta-analysis of research on vocabulary instruction and comprehension by Stahl \& Fairbanks (1986) reviewed 52 studies to analyze effective methodologies and reading-vocabulary relationships impacting student understanding and achievement. The teaching methods employed in each study were used to classify the research onto one of three categories delineating the theory used: emphasis on context, depth of processing principals, or quantity and quality of exposures. Research was further divided by setting factors: time allotment to teaching vocabulary and group vs. individual instruction. Grade levels of the studies ranged from kindergarten to college. A mean effect size of 0.97 was determined in regards to the effect of vocabulary instruction on the reading comprehension of passages containing taught words, signifying a reliable positive correlation (p. 100). These results were not found in all teaching methods though, and the researchers concluded that "mixed" methods were the most effective in increasing comprehension. Instructional practices involving both definitional and contextual information for unfamiliar words produced higher assessment scores than methods such as drill-and-practice that only use associative processing. Stahl \& Fairbanks concluded through this meta-analysis that "the effects of vocabulary instruction are subtle and 
complex, but, given their potential effects on comprehension, they are worthy of further investigation" (p. 104). The following two papers on instructional methods, although absent scientific measurement and quantifiable data, provide examples of strategies in practice.

Young (2005) provides five Engaged Learning Vocabulary Strategies intended to support understanding and interest in the language of science. These inquiry-based strategies are designed to increase students' listening, reading, writing, and speaking vocabulary through multiple exposures, relationship building, and contextualized word meaning activities. The author suggested that students, who are actively engaged in their own learning of science vocabulary, and those who are encouraged to collaborate with their peers, will develop an interest in the content area and form associations between the subject matter and their own prior experiences and knowledge. Young recommended teachers implement a Science Vocabulary Questionnaire before presenting new vocabulary in order to examine student thinking and again after using word-meaning content strategies as a post-evaluation or reflective tool. Inquiry methods proposed in this article include Vocabulary TV Visualization (Young 1996), Definition Maps, Personal Clue Cards, Rate Your Words, and Semantic Feature Analysis. Each of these engaged learning strategies call upon students to apply metacognitive abilities, develop associative thinking and work in collaborative groups, as well as independently. Young's methods encourage educators to use instructional time teaching the language of science prior to teaching the complex content matter. Content literacy mastery is noted as a students' ability to "...effectively communicate knowledge with a high degree of competency and 
expertise" (p. 15). The engaged learning vocabulary strategies presented in this article are proposed to assist instructors in bringing students closer to the objective of content mastery.

Carnine \& Carnine (2004) suggested the implementation of multiple instructional design strategies to integrate science content with reading skills. The methods and practices presented are intended to increase the success of struggling students, emphasizing textbook comprehension, vocabulary retention, oral reading ability and the application of higher order thinking. The authors proposed teachers begin by assessing students' oral reading fluency, as it is "highly correlated with and predictive of reading comprehension". This strategy is intended to build reading fluency as students reread science material passages and track their own progress, noting the number of words read and errors made with each iteration. Vocabulary understanding and retention is claimed to increase as teachers carefully select relevant, multisyllabic words to be taught explicitly with daily instructional activities and tests. Carnine \& Carnine also emphasized the importance of teaching prefixes, suffixes and affixes commonly found in scientific terminology (e.g., bio-, and -ology). Partner re-tell activities and read aloud times also contribute to a teacher's repertoire of science literacy strategies proposed by the authors. Science content instructional strategies suggested in this publication emphasize: core concept/big idea focus, integration of core concepts into higher order concepts, visual displays to enhance connectivity, utilization of mnemonic devices, and implementation of hands-on activities. The instructional design techniques laid-out in this article blend content-based curriculum material with reading skill strategies through various methods 
adaptable to both middle and upper grade levels. Concessions made by the authors examined the role of other ingredients in educational settings that affect our ability in "meeting the challenges of limited reading skills and complex, extensive content". Insufficient instructional time, discipline programs, and progress monitoring are listed amongst the variables affecting student and teacher success in implementing a valid curriculum design program to address science content and literacy.

The preceding research studies establish a measurable relationship between the explicit instruction of vocabulary in the classroom and increased student achievement. This achievement comes in the form of content knowledge, reading comprehension, and proficiency in standardized test scores. These studies have emphasized the need for vocabulary teaching on the whole-school level, not just through the language arts department. The quantitative and anecdotal reflections presented here have two recurring themes for educators to teach vocabulary effectively: designate explicit time for vocabulary instruction on a regular basis and provide students with a relatable context for unfamiliar words and terminology. The depth and breadth of vocabulary in scientific disciplines exacerbates those time demands and simultaneously stresses the need for methodical instruction. The following section considers another component in the discussion of how students acquire scientific content knowledge: oral communication.

\section{Oral Communication Skills and Scientific Literacy}

Spektor-Levy, Eylon \& Sherz (2009) conducted a longitudinal study of 202 junior high students evaluating the impact of the teaching program "Scientific Communication" 
$(S C)$ skills on student achievement and scientific literacy. The authors first defined and categorized the higher-order skills and sub-skills the "Scientific Communication" instructional program would emphasize as: information retrieval, scientific reading and writing, information representation and knowledge presentation. Knowledge presentation sub-skills included oral presentation abilities, a key final assessment measure for the success of this study. Comparing students who received structured instruction (SI) and/or practiced performance tasks $(P T)$ of scientific communication skills to a comparison group without intervention, the researchers aimed to disprove an underlying assumption common in science curricula: that attainment of scientific communication skills will occur spontaneously, without planned intervention. Subsequently, student groups received explicit teaching of scientific communication skills and/or multiple opportunities to employ short performance tasks, such as researching a topic and answering questions from peers through the role of an expert. After two years of spiraled instruction in $S C$ skills (as part of the $S I, P T, S I+P T$, or comparison group), students were evaluated through a culminating task, demanding the implementation of research, content knowledge and oral presentation skills. Results demonstrated a mean content knowledge score difference of 21 points between the comparison group and the students who received both $S I$ and $P T$ instruction, respectively. The comparison group also trailed their peers in $S C$ skills, overall performance, and the quality of learning products. Students who participated in the "Scientific Communication" program demonstrated improved use of professional terminology and meta-cognition of the skills demanded for acquiring and presenting scientific knowledge. Spektor-Levy et al. concluded that the 
systematic teaching of scientific communication skills, such as oral presentations and opportunities for peer-to-peer scientific discourse, can help develop a literate student population ripe with scientific content knowledge. Research on the role of scientific communication skills in the acquisition of content knowledge can be further tested through the specific higher-order thinking task of argumentation.

Zohar and Nemet (2001) examined the role of oral argumentation skills in fostering student's biological knowledge through dilemmas in human genetics. Their research evaluated students' abilities to communicate biological knowledge, both written and orally, when explicitly taught argumentation skills. Acknowledging science as a social activity, Zohar and Nemet employed the interactive Genetic RevolutionDiscussions of Moral Dilemmas curriculum in five heterogeneous Israeli classrooms consisting of 99 students, over a 12 lesson unit. A comparison group of 87 students in four classes was also evaluated for achievement gains, but did not receive direct, instructional intervention. The curriculum included content lectures on human genetics, such as X-linked traits and heredity, in addition to subject matter such as genetic cloning and gene therapy. Students in the experimental group were presented with moral dilemmas regarding human genetics (e.g., should a fetus be aborted if both parents are known carriers of the gene for Cystic fibrosis?) and asked to use argument supported by scientific evidence to analyze their own position both before and after explicit instruction of argumentation skills. Pre- and post-intervention transcripts of audiotaped student discussions were analyzed, qualitatively categorized and subsequently scored for student's use of biological knowledge in constructing complex arguments. The results of 
this analysis for the experimental group showed each student's discourse to include more explicit conclusions and justifications for reasoning post-intervention. Additionally, students who had received explicit instruction and practice in argumentation skills spoke for longer periods of time, suggesting "an increase in the complexity and richness of their discourse" (p. 55). A post-test comparison of whether or not students consider biological knowledge in constructing an argument, resulted in $53.2 \%$ of the experimental group making correct considerations, compared to $8.9 \%$ of the comparison group students. Zohar and Nemet concluded that oral and written argumentations techniques are not mutually exclusive from the methods used by students to effectively learn content knowledge; learning communication skills allows students to synthesize content specific information with higher-order thinking through meta-cognition and the social constructs of learning. How students synthesize content knowledge and how their related proficiency in orally communicating that information is the subject matter of the next qualitative research example.

A case study by Crawford (2004) addressed the need for multiple discourse methods and opportunities for students to communicate competence in scientific knowledge and practice. This research analyzed an urban fourth grade student's ability to demonstrate knowledge of engineering design, practices and scientific concepts in a unit introducing the concept of work through a pulley system. Crawford compared this student's competence in expressing scientific understanding through both written and oral discourse in the form of an engineering report and an oral presentation explaining the mechanisms of a pulley system, respectively. During the oral presentation, the student 
under examination, chosen for his low reading and writing ability levels in science, used scientific terminology, analogy and actively participated in a "dynamic interchange of questions and challenges by the community members (peers), and clarification attempts" for 19 minutes (p. 153). The student's oral discourse was transcribed, coded, categorized and labeled in terms of demonstrated scientific practices and ultimately compared to the written discourse of the engineering report. An analysis of the two methods of scientific discourse found the student's writing abilities to inaccurately portray his actual knowledge and functional understanding of pulley systems. The written statements lacked clarity and conceptual understandings quantitatively and qualitatively present in the oral presentation. Crawford uses this case study to argue for the inclusion of multiple discourse opportunities, as communicative competence and academic knowledge may be demonstrated best through oral presentation for many students. The author concluded that students with limited proficiency in reading and writing may not be fairly assessed without the opportunity to demonstrate scientific knowledge through oral communication; representing the social and discursive nature of science.

In summary, teaching the specific skills needed for scientific communication is an important element in student success; the ability to present and discuss concepts and viewpoints does not occur spontaneously. Further supporting this assumption is the work of Zohar and Nemet (2002), who presented evidence that students will use evidence and reasoning in scientific argument and discourse if given the opportunity to practice and understand the relevance of said skills in performing to par. Expressing understanding and knowledge orally can be especially important to students who may not yet thrive in 
writing abilities, but can demonstrate competence with confidence through their voice. Student samples in the previous studies, diverse in age, geography and academic ability, consistently demonstrated improved scientific literacy after experiences with skills-based educational opportunities in oral communication. The final section of this literature review will address some of the factors that may impact students' abilities in oral communicators.

\section{Impediments and Enhancers in Oral Communication}

Smith and Sodano (2011) examined issues affecting student's competence and confidence in oral presentation skills through surveys and lecture capture technology. Participants in this study used self-assessment to critique their classroom presentation skills as the researchers evaluated the possible role of "podcasting" student presentations as a tool to enhance their abilities. In a cross-disciplinary experiment, 53 undergraduate students at a small liberal arts college were randomly divided into an experimental or comparison group and assigned three post-presentation surveys as measurement instruments and data collection. The experimental group, a mix of nursing and journalism students, was provided a podcast of their presentation to view and self-assess before completing the surveys. Surveys used Likert scales and yes/no responses for data analysis of four student characteristics: comfort in using technology, perceived expertise in presenting, comfort with their presentation skills, and learning preference (p. 156). Results of this survey analysis showed little significant difference between the two groups, but demonstrated consistently low evaluation of competencies in oral 
presentations. The competency item assessing the appropriate use of pronunciation, grammar and articulation averaged 1.34 on a Likert scale of 0-2 (unsatisfactory, satisfactory, and excellent). Smith and Sodano concluded that students were "consistently anxious and lacked self-confidence when presenting". Survey responses also declared a preference by students for hands-on practice with presentation skills and it was suggested that all faculty explore instructional methods to develop student confidence and reduce anxieties. The authors recommended that teachers cultivate oral communication abilities in addition to content knowledge to improve students' confidence and competence in this essential skill. The final study presented in this literature review examines a method intended to support the development of oral communication skills in students.

Dunn (1989) studied the effect of pronunciation exams and associated writing exercises on vocabulary development in college biology students. A large working vocabulary, defined as "terms they understand and use in common speech", is essential for students to be successful and credible in scientific fields of study as well as other professional circles (p. 176). To build vocabulary, Dunn first acknowledged two common challenges for biology students: pronouncing technical terms with multiple syllables, and mastering words with different meanings but similar pronunciations. These impediments to substantial, scientific working vocabularies are thought to detract from students' scientific communication, confidence and the development of corollary writing skills. Multiple teaching strategies were proposed to address phonetic deficiencies in the college classroom including: pronunciation exams, vocabulary matching exams, phonetic spellings written on the board, and reinforcement of terms through lecture and lab 
discussions. Dunn also suggested teachers instruct students on the roots and component parts of scientific words to increase memory and understanding. Writing in a grammatically correct, understandable manner that incorporates vocabulary, was also presented as a reinforcement tool for teachers to develop their student's working vocabulary and comprehension of concepts. The use of science journals, expressive writing, and data-supplied micro-themed essays were posited to increase mastery of content and development of critical thinking skills. Dunn's article and position are absent of technical data, instead referencing anecdotal classroom experiences that demonstrated growth in students' comfort and engagement using scientific vocabulary as each semester progressed. Dunn concluded that pronunciation exams and additional vocabulary development strategies aided in transitioning students from using the nonscientific term "hookworm" at the beginning of the course, to publicly professing the parasite's Latin name Ancylostoma at each term's end.

Smith and Sodano (2011) noted that a common theme reported by students in reference to oral presentation skills was that of anxiety and a lack of self-confidence. While providing students with an opportunity to review and learn from their own performances, the prevailing conclusion was that learners feel they would benefit most from chances to practice their developing skills. Inexperience was deemed a noteworthy inhibitor to confidence and competence in presentational oral communication. The qualitative analysis by Dunn (1989) proposed that an inhibitive factor in student's oral communication abilities in scientific disciplines centers on abstract vocabulary that challenges students' pronunciation abilities. Pronunciation of new, multisyllabic 
terminology impedes confidence in using these words in a public setting, open to peer evaluation. Combined, the previous studies present a challenge in teaching students the strategies of oral scientific communication as a potential instructional methodology for improvement.

\section{Summary}

The comprehension of academic and discipline-specific vocabulary has been shown to increase high-school students' standardized test scores in addition to affecting their peer-to-peer and classroom-centered discourse abilities. Vocabulary acquisition has correlated with gains in content understanding and supports the use of explicit instruction that may be implemented through a variety of science literacy-based instructional methods (Fisher 2007; Townsend et al. 2012). Strategies for teaching science vocabulary emphasize repetition, context and speaking words aloud in addition to reading and writing.

The studies presented in this literature review have acknowledged the need for oral communication skills in the next generation of scientists and recommended methods secondary school science teachers can employ to nurture these skills. The explicit instruction and repetition of argumentation and science communication skills needed to become confident and competent in oral discourse are recommended by Spektor-Levy, Eylon \& Sherz (2009), Zohar \& Nemet (2001) and Crawford (2004). Another method centers on the role of pronunciation in increasing student confidence in oral communication of scientific vocabulary (Dunn 1989). While Dunn's study focused on 
college students, the skills needed for undergraduate success must be initiated in high school.

In light of the previous research, this study explores methods designed to overcome impediments to student competence in oral presentations (i.e., lack of confidence and anxiety over the unfamiliar) as presented by Smith and Sodano (2011) by employing vocabulary literacy strategies in the classroom (Young 2005; Carnine \& Carnine 2004), specifically those that emphasize pronunciation of scientific vocabulary. Dunn (1989) stated that "when students use new terms instead of street parlance while talking to one another, an instructor can suspect he's made an impression." 


\section{CHAPTER 3: METHOD}

\section{Method Overview}

The objective of this study was to answer the research question: Can the frequency and propensity of student participation in class discussion be increased by instruction in the pronunciation of scientific vocabulary? Both quantitative and qualitative methods were used for data collection. The frequency of which individual students participated in class discussions were tallied numerically before and after explicit instruction in proper pronunciation of new scientific terminology. The number of different students who spoke aloud in class to pose or answer questions during guided discussions was counted along with the number of times each student spoke. Interviews were conducted to gain insight into the students' perceptions of the instruction and how it may have affected (or failed to affect) their willingness to participate in class discussions. A pre- and post-treatment survey with both Likert scale and open-ended questions was also used to qualitatively assess students' appreciation for and perceived benefits of pronunciation instruction in their confidence and competence in scientific discourse.

The intent of this research was to develop an externally valid, generalizable method to increase student participation in class discussions. The independent variable employed was explicit instruction in pronunciation. The explicit teaching strategies of the intervention focused on three primary aspects of pronunciation: 1) recognizing common word roots, prefixes, affixes and suffixes in biology 2) using phonetics to break down polysyllabic words into manageable parts and, 3) repetitive practice in speaking vocabulary terms aloud in pairs, small groups and whole class activities. The dependent 
variable measured was the frequency of student participation in class discussions after receiving pronunciation instruction compared to the no-treatment, control studies.

A causal relationship was established by use of repeated measures quasiexperimental research design comparing two study classes and two curricular units where each class participated in one iteration of the treatment and one without (Table 1). Using this design Group B received the treatment during the first period of the study, over 4 weeks, while Group A served as the control. After initial data was collected the roles reversed and Group A received the experimental treatment for four weeks while Group B served as a control. However, since Group B received the treatment during the prior unit it was predicted that the students in Group B would continue to be more comfortable speaking in class.

The fundamental theory supporting this study was that an increased ability to speak the language of science would increase the likelihood that students would become active speaking members of the classroom and scientific community.

Table 1: Experimental design

\begin{tabular}{|c|c|c|c|c|c|c|}
\hline Timeline: & $\begin{array}{l}\text { Pre- } \\
\text { intervention: } \\
\text { unit 1 }\end{array}$ & $\begin{array}{l}\text { Instructional } \\
\text { unit 1 }\end{array}$ & $\begin{array}{l}\text { Post- } \\
\text { intervention: } \\
\text { unit 1 }\end{array}$ & $\begin{array}{l}\text { Pre- } \\
\text { intervention: } \\
\text { unit 2 }\end{array}$ & $\begin{array}{l}\text { Instructional } \\
\text { unit 2 }\end{array}$ & $\begin{array}{l}\text { Post- } \\
\text { interventio } \\
\text { n: unit 2 }\end{array}$ \\
\hline $\mathrm{N}_{\mathrm{a}}$ & $\mathrm{O}_{\mathrm{F}}$ & ------- & $\mathrm{O}_{\mathrm{F}}$ & $\mathrm{O}_{\mathrm{S}, \mathrm{O}_{\mathrm{F}}}$ & $\mathrm{X}$ & $\mathrm{O}_{\mathrm{F}}, \mathrm{O}_{\mathrm{S}}, \mathrm{O}_{\mathrm{I}}$ \\
\hline $\mathrm{N}_{\mathrm{b}}$ & $\mathrm{O}_{\mathrm{S}}, \mathrm{O}_{\mathrm{F}}$ & $\mathrm{X}$ & $\mathrm{O}_{\mathrm{S}, \mathrm{O}_{\mathrm{F}}}$ & $\mathrm{O}_{\mathrm{F}}$ & ------- & $\mathrm{O}_{\mathrm{F}} \mathrm{O}_{\mathrm{I}}$ \\
\hline
\end{tabular}

Key: $\mathrm{N}_{\mathrm{a}}=$ non-randomized study Group A $\mathrm{N}_{\mathrm{b}}=$ non-randomized study Group B $\mathrm{X}=$ treatment; instruction in pronunciation
$\mathrm{O}_{\mathrm{S}}=$ pre- and post- treatment surveys

$\mathrm{O}_{\mathrm{F}}=$ frequency of participation in class discussion data collection

$\mathrm{O}_{\mathrm{I}}=$ interviews 


\section{Participants}

This research took place in two high school biology classes at Southridge High School in the Beaverton School District. The student participants were sophomores and juniors with demographics representative of the greater Portland metro area. Intact classes with pre-assigned students will made up the study groups as opposed to a random assignment. Group A consisted of 27 participants and Group B had 22 participating students, giving a total sample of 49 .

\section{Treatment}

The experimental intervention used in this study combined multiple elements of vocabulary and pronunciation instruction referenced across numerous bodies of literature. This research adapted and merged methods from the communication and literacy in science education disciplines to align with the goals of the treatment strategy.

The intervention employed various teaching techniques in pronunciation instruction aligned with proven vocabulary comprehension strategies. The initial intervention, at the beginning of the unit lasted for approximately 30 minutes, introducing the participants to the methodology. Subsequent instruction in vocabulary comprehension and pronunciation occurred for 15 minutes at the beginning of three lessons across the curricular unit. The final intervention activity, a review game, took approximately 45 minutes of class time. Activities and coursework that further students' understanding of the topic at hand (genetics or evolution) proceeded for the remainder of each 90 minute period, but pronunciation was not specifically taught. These methods were the same for 
each study group during the experimental portion of the research, but contained different vocabulary words appropriate for the content to be learned (Appendix C: Vocabulary Terms). The control unit for each study group was given the same vocabulary word meanings as the experimental unit, but the emphasis on pronunciation was withheld. Specific words to be taught were chosen based on the recommendations of Fisher (2007): key terms must be representative of the concept, repeatable through the school year, have a structure that can be analyzed to determine word meaning, and have meaning that can be determined by contextual clues. Fisher (2007) also supported minimizing the cognitive load so students are not expected to learn an excessive number of words at one time. This study limited new words to five per day, and only introduced new terms in alternating class periods to allow time for multiple exposures (Young, 2005) and understanding of overarching concepts. The following section outlines the instructional methods used and the literature supporting those strategies, within the context of a treatment timeline (see Table 2 for a summary of treatment lessons and corresponding strategies from the literature): 
Table 2: Treatment lesson plans and corresponding instructional strategies from the literature

\begin{tabular}{|c|c|c|}
\hline Treatment Lesson Plan & $\begin{array}{l}\text { Marzano's Six-Step Process for } \\
\text { Teaching New Terms (2004) }\end{array}$ & $\begin{array}{l}\text { Murphy's Scale of Activities for } \\
\text { Accuracy in Oral } \\
\text { Communication by Proficiency } \\
\text { Level (1991) (adapted) }\end{array}$ \\
\hline $\begin{array}{l}\text { 1. An Introduction to } \\
\text { Linguistics and Vocabulary } \\
\text { Flashcards }\end{array}$ & $\begin{array}{l}\text { Step 1: Explain } \\
\text { Step 2: Restate } \\
\text { Step 3: Show* }\end{array}$ & $\begin{array}{l}\text { - Repeating after a speaker } \\
\text { - Self-initiating the production } \\
\text { of isolated words }\end{array}$ \\
\hline 2. Read-Alouds & Step 4: Discuss & $\begin{array}{l}\text { - Repeating after a speaker } \\
\text { - Reading out loud from written } \\
\text { text }\end{array}$ \\
\hline $\begin{array}{l}\text { 3. } \\
\text { Science Words and } \\
\text { Storytelling }\end{array}$ & Step 5: Refine and Reflect & $\begin{array}{l}\text { - Repeating after a speaker } \\
\text { - Practicing conversational } \\
\text { speech }\end{array}$ \\
\hline $\begin{array}{l}\text { 4. Terminology and } \\
\text { Technology }\end{array}$ & Step 5: Refine and Reflect & $\begin{array}{l}\text { - Repeating after a speaker } \\
\text { - Engaging in oral } \\
\text { interpretation exercises }\end{array}$ \\
\hline 5. Reverse Jeopardy & $\begin{array}{l}\text { Step 6: Apply in Learning } \\
\text { Games }\end{array}$ & \\
\hline
\end{tabular}

*Steps 1-3 will be completed by each student as homework for the remainder of the intervention by completing each quadrant of their Flayer-model flashcards for each vocabulary word

\section{Lesson 1: An Introduction to Linguistics and Vocabulary Flashcards.}

Teaching word origins, in the form of Greek and Latin prefixes, suffixes and roots has been shown to equip students with the skills needed to decipher unfamiliar words (Milligan \& Orlich, 1981). The first day of intervention in this study began by giving students a list of the words parts they would encounter throughout the unit (e.g., -ology, hydro-, -anthro-). Donald Ayers book Bioscientific Terminology: Words from Latin and 
Greek Stems was used as a resource to accurately define word parts and meanings.

Students were asked as a class to write the definitions of the word parts in their science notebooks and to say them aloud after the teacher. This Direct Method of Audiolingualism (i.e. repeating after the speaker) was used throughout the intervention when new words were introduced (Murphy, 1991).

After the introduction to linguistics, students were given their first five vocabulary words and introduced to the context and objectives of the unit. Students were also told about the importance of attempting accurate pronunciation in scientific discourse and how this would be emphasized throughout the unit. They were then asked to work with a partner to deduce possible word meanings based on the Word Parts Chart. Students shared their self-created word meanings with the class followed by teacher-led definitions, using student-friendly explanations (Marzano, 2004) and another round of repeating after the teacher.

Murphy (1991) describes classroom activities for producing oral accuracy on a scale based on student proficiency; after mimicking the speaker's pronunciation, it is recommended that students be allowed to self-initiate the production of words. Marzano's Second Step (2004) in vocabulary development suggests students restate definitions in their own words to form cognitive connections. The second stage of the first lesson intervention combined these vocabulary and oral communication strategies by having students create adapted Frayer-model vocabulary notecards showing the new term, their own definition and the phonetic spelling that makes the most sense to them (Figure 1). Students then shared their definitions and phonetic spellings with a small group before 
being given the opportunity to share with the whole class. The associated homework assignment for each stage of the treatment was for students to follow Marzano's Third Step for Teaching New Terms (2004) and draw a picture or other graphic that illustrates the term. Treatment during first lesson in the control unit also employed the instruction of word parts and creation of vocabulary flash cards, but was absent the beginner level audiolinguistic repetition strategies described by Murphy (1991). As shown in Figure 1, Frayer-model vocabulary word cards used in the control unit mimicked the original design, absent of the phonetic spelling portion.

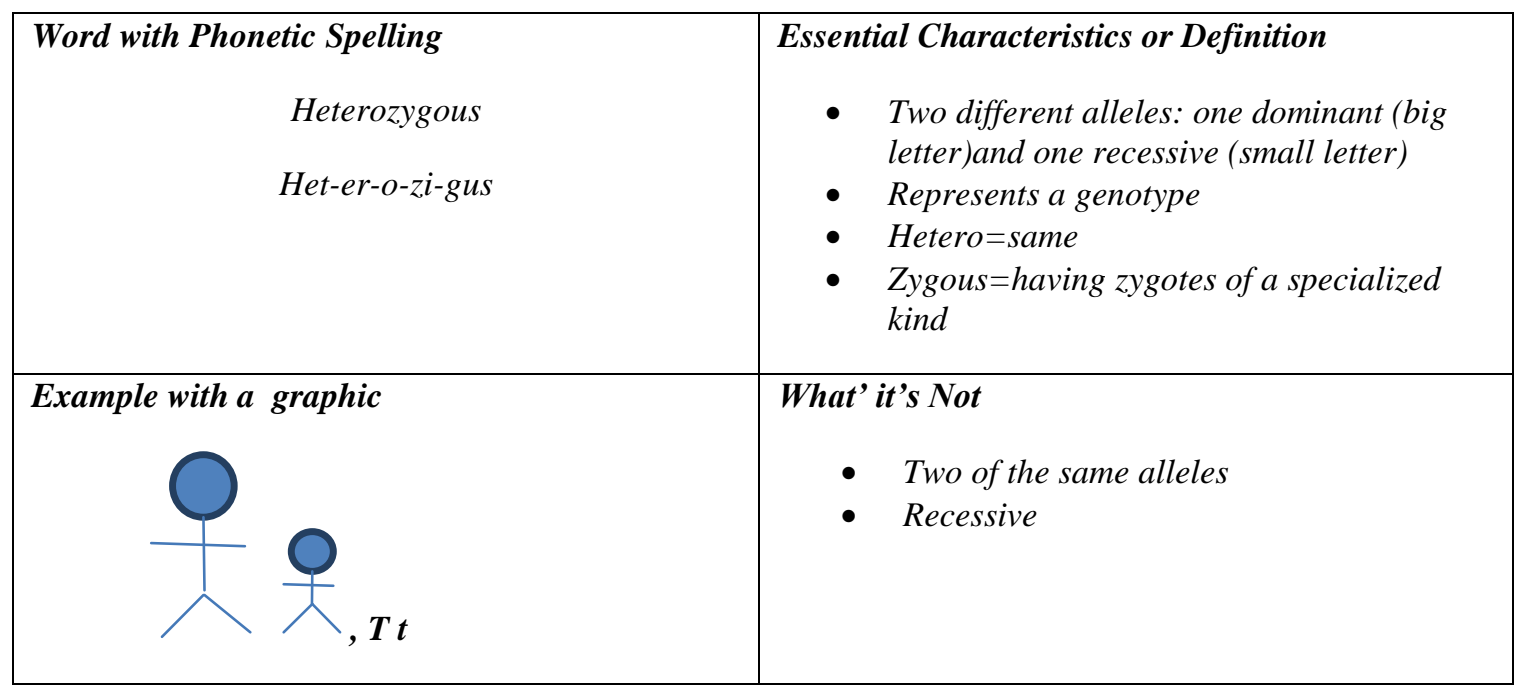

Figure 1: Adapted Frayer-model vocabulary flashcard with phonetic spelling - treatment 


\begin{tabular}{|c|c|}
\hline Word & $\begin{array}{l}\text { Essential Characteristics or Definition } \\
\text { - Two different alleles: one dominant (big } \\
\text { letter)and one recessive (small letter) } \\
\text { - Represents a genotype } \\
\text { - Hetero=same } \\
\text { - Zygous=having zygotes of a specialized } \\
\quad \text { kind }\end{array}$ \\
\hline Example with a Graphic & $\begin{array}{l}\text { What' it's Not } \\
\text { - Two of the same alleles } \\
\text { - Recessive }\end{array}$ \\
\hline
\end{tabular}

Figure 2: Adapted Frayer-model vocabulary flashcard without phonetic spelling - control

Lesson 2: Read-Alouds.

On the second day of the intervention, students again practiced speaking five new vocabulary words as a whole class and added these new terms and phonetic spellings to vocabulary flashcards. Students then take turns with a partner saying each of the vocabulary words used so far. In small groups, students read aloud sections from a short textbook passage related to the subject matter and reflected using a jigsaw format. Reading aloud from written text continues to advance students on the proficiency scale proposed by Murphy (1991) and supports Marzano’s Fourth Step (2004) to reinforce vocabulary understanding, by having students discuss terms with one another within the context of the subject matter. Students in the control unit or group read passages silently before participating in the jigsaw format reflection within small groups. 


\section{Lesson 3: Science Words and Storytelling.}

In this step of the treatment, students will again practice pronunciation by repeating five new vocabulary words after the teacher and recording definitions and phonetic spellings on their vocabulary flashcards. Students will then refine their skills through an activity to develop higher order thinking skills the ability to employ scientific terminology in speech (Murphy, 1991). In this 15-minute intervention period, students will be asked to choose four of the words they have been introduced to and quickly develop a short, creative story incorporating each word. Students will then be asked to share their story aloud with a partner and be offered the chance to share it with the whole class. Practicing conversational speech (Murphy, 1991) and reinforcing terminology (Marzano, 2004) are both strategies to allow students opportunities to refine their pronunciation and to use multisyllabic scientific terms in dialogue. The control unit or group will also create a story using scientific terminology and share it with their peers, but will not be asked to emphasize and practice the pronunciation of the chosen vocabulary words.

\section{Lesson 4: Terminology with Technology.}

On this final day of introducing new vocabulary words and strategies to the class, we again began with whole-group vocal repetition of the terms and adding phonetic spellings to the flashcards. The next step of the treatment plan allowed students access to their smartphones or classroom computers where they were told to access

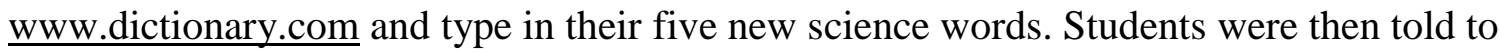


use the audio feature of the website and listen to the pronunciation and repeat what they heard. ESL students also had this opportunity to hear the pronunciation in another language if the word could be found in the translation function of the website. After listening to their words online, students were asked to discuss any discrepancies they found between their own pronunciations, their peers, their teacher's, and the computer audio recordings. This portion of the treatment was designed to engage students with technology as well as to provide further opportunity to practice, refine and reflect on oral communication in scientific discourse and word meanings. Students in the control group or unit were asked to research definitions of the new words online and translate them in their own words onto their vocabulary flashcards.

\section{Lesson 5: Reverse Jeopardy.}

In the final stage of the treatment, the teacher adhered to Marzano's Sixth Step (2004) in teaching new terms by applying terminology to a game. In this version of Jeopardy, teams were given the description of a term, a visual representation or a scenario involving the word in question and the first team to "buzz in" and speak aloud the correct vocabulary word correctly received points. Each student from each team must have spoken once before any student in a group may speak twice. The control group will played this learning game as well, but again, without emphasis on pronunciation and students were not told that each member of a group must speak once. This final experimental lesson was designed to ensure that each student was given the opportunity to engage in and have their voice heard in whole-class activities. 
Differences between the experimental groups that may have affected implementation of the treatment are consistent with those of many educational research studies. Exceptional learners such as special education students, English language learners and students with behavioral challenges can affect the teacher-researcher's ability to provide standardized instruction to all participants at all times.

Accommodations for students with special needs effecting research design were not necessary for this particular group of student participants.

\section{Instruments}

Three separate instrument types were used to collect qualitative and quantitative data. The frequency of students' vocal participation in class discussions was be tallied at four separate intervals for each study group, pre- and post-intervention. This quantitative measurement tool assessed the actual number of times each student voluntarily engaged in scientific discourse, as well as the quality of those comments in terms of vocabulary use and accurate expression of scientific concepts. Post-intervention interviews were administered to six students in an individual, open-ended question format and were subsequently coded for common themes amongst responses. A survey was given to each participant before and after treatment using a Likert scale and open-ended questions assessing students' beliefs and opinions in regards to pronunciation of scientific vocabulary and factors that affected their participation in class discussions. 


\section{Frequency of Student Participation and Use of Scientific Vocabulary:}

Appendix A illustrates the data collection form that was used to tally the frequency of each student's participation in 30 minute guided class discussions. The specific format of the guided discussions was determined by the biology content of the unit and scheduled class activities; and included homework sharing activities, concept review and teacher led question and answer session during lecture notes in the form of PowerPoint presentations. Individual student names were marked each time they voluntarily: 1) answered a question posed by the teacher or another student, 2) asked a question of the class or the teacher, 3) spoke during a whole-class activity (i.e., homework review, presentation of research findings, sharing understandings, etc.) and/or, 4) communicated using a scientific vocabulary word or concept from either of the two curricular units employed during the study period. This instrument was used with each study group one week before treatment, and again one week after the intervention. The same timeline was used with the control instructional units for each class group. Pretreatment data collection for the first unit (Genetics content) was collected over three class periods at the end of an instructional unit on Cellular Processes. Post-treatment data collection for the Genetics unit occurred during the final three days of instruction within that unit, which had incorporated the treatment lessons. This design allowed for comparison of participation rates at the completion of a unit with the treatment (Genetics) and one without (Cellular Processes). Pre- and post-treatment frequency of participation data for the second unit of instruction occurred at the beginning and end of Evolution 
curriculum. Vocabulary words used from any prior instructional unit were tallied and ranked accordingly.

Analysis of the data collection form tallied the number of times each student spoke before treatment and compared that frequency to post-treatment totals. Whole-class comparisons in verbal participation were calculated from this instrument as well. Additionally, student comments were ranked on the following 4 point scale: $0=$ comments not related to the content are made, $1=$ content is referenced, but without using a vocabulary word, $2=$ a vocabulary word is used, but context is inaccurate or, $4=$ vocabulary word and context are correct. Reliability of this instrument was ensured by having the mentor science teacher tally student participation at each iteration as opposed to this researcher. Face validity was determined by the judgment of two professionals in science education research who agreed that the instrument provided a satisfactory measurement of student participation in class discussions.

\section{Survey of Student Self-Efficacy in Scientific Discourse:}

A pre- and post-intervention survey (Appendix B) was given to all students in each study group at the same time as the frequency of participation data was collected. The intent of this survey was to assess: 1) students' perceived confidence in oral communication during biology class; 2) inhibiting factors affecting their participation in whole-class guided discussions; and 3) the perceived benefits, or lack thereof, in being taught pronunciation of bio-scientific terminology. This instrument combined aspects of surveys designed by Smith \& Sodano (2011), Curto \& Bayer (2005), and Young (2005), 
all of which were designed to assess student's confidence as speakers. Each survey was originally used in research evaluating the role self-efficacy in oral scientific

presentations. The revised and adapted version of the survey used in this study included 6 items using a 5-point Likert scale and three open-ended questions. The validity and reliability of the Likert scale survey items can be referenced in Smith \& Sodano (2011) Personal Report of Confidence as a Speaker short form and the Initial and Follow-up Survey Questions by Curto and Bayer (2005). Question 8 is adapted from Young (2005) Pre- and Post-evaluation Science Vocabulary Questionnaire. The researcher-designed open-ended questions addressed student preferences and perceived usefulness in practicing pronunciation and were evaluated for face validity by two science education and research professionals. The open-ended questions were repeated during the interviews for additional validation.

\section{Student Interviews:}

Six students were interviewed at the end of the second instructional unit. All students had received two hours of instruction and practice in pronunciation and completed all unit assessments prior to the interview. Five open-ended questions were asked of the participants, with follow-up questions for clarification when necessary. The six interviewees did not represent a statistically significant proportion of the study sample size and responses were used solely to add qualitative depth to survey responses and participation data. These interview questions were designed to evaluate student's 
perceived effectiveness of the strategies used in the treatment. The following questions were asked of each participant:

1. Do you speak often in class? What influences your decision to speak? What could make you speak more?

2. In the last two units, genetics and evolution, we used five different ways to practice vocabulary: flashcards, dictionary.com, letter writing, reading the textbook in groups, and playing review games. Which of these helped you learn the words the most? Which helped the least?

3. When do you use a "science word" instead of just a description? What helps you use the vocabulary word instead?

4. Did learning and practicing how to pronounce scientific vocabulary words effect your participation in class discussions? Why or why not?

5. Did learning how to pronounce vocabulary words help you learn or remember the meaning of those words?

Interview responses were coded for recurring themes and qualifications of the intervention. The validity of these questions was evaluated by two science education research professionals.

\section{Procedure}

This study took place during the fall and winter semesters of the 2012-2013 academic year at Southridge School within a regular Biology classroom. The treatment (instruction in vocabulary pronunciation) occurred over five days of lessons within a curricular unit, one teaching genetics and one unit of evolution. Experimental and control instructional units were opposing for each class with Group B receiving the treatment during the genetics unit and Group A receiving the treatment during evolution instruction. Frequency of participation data was collected for both study groups by the cooperating mentor teacher during guided discussions one week prior to and one week 
after each experimental and control curricular unit of the study. Guided class discussions pre- and post-intervention were led by the researcher with frequency of participation data compared between groups and between units to assess validity. The 15-minute interactive mini-lessons of the treatment, 30 minute initial lesson and 45 minute review lesson were also taught to each study group by the researcher. Surveys were given to all participating students before and after the experimental unit only. Data collected from the surveys was not evaluated until the end of the study to avoid researcher bias during instruction. Interviews of six students occurred after the completion of the second teaching unit and were conducted by the researcher during student free periods. Interview subjects were randomly chosen based on responses to survey question 9; the names of students who stated that instruction in pronunciation positively affected their verbal participation in class discussions were separated from those who declared otherwise and three names were drawn from each pool.

\section{Data Analysis}

Internal validity of this causal study was assessed using descriptive and inferential statistics (Trochim, 2006). Frequency distribution measurements were used to describe the variable rankings of student comments tracked with the Student Use of Scientific Vocabulary instrument (Appendix A). Means and standard deviations were calculated to analyze the central tendencies of participation data within experimental and control units and between sample classes. The central tendencies of Likert scale survey responses were 
analyzed using descriptive statistics. Selected open-ended survey questions and interview responses were separately coded and categorized for recurring phrases and themes using grounded theory.

Two-Variable Linear Models were established to analyze potential correlations of individual student's pre-and post-treatment participation rates as determined by the total number of comments made that scored a 2 or above. The statistical significance of differences between means were compared using one-tailed unpaired Student's t tests. 


\section{CHAPTER 4: RESUlts}

\section{Gains in Verbal Participation}

Overall gains in students' verbal participation in class discussions was determined by tallying the total number of comments made by individuals during 45 minute intervals over three class periods pre- and post- intervention using the Student Use of Scientific Vocabulary instrument (Appendix A). The difference between the total number of preand post- values is qualified as student verbal participation gains. Descriptive and inferential statistics were used to calculate differences in the mean number of comments made per student within and between treatment and control groups for the first and second units of instruction. A summary of the mean verbal participation gains for control and treatment groups over Units 1 and 2 is shown in Table 3.

The average number of comments made by students in the control group (A) increased by 1.19 over the course of the first unit $(\mathrm{SD}=3.30)$. A slightly higher increase can be found in the treatment group (B), those students exposed to the vocabulary and pronunciation lesson activities, with a gain in the mean number of comments made by $1.77(\mathrm{SD}=3.41)$ in Unit 1 (Table 3). The two classes from the first unit were switched for the second unit with the original control group now receiving the treatment and vice versa. Results in the mean gain in student participation show an increase in verbalization for both groups in the second unit second unit, with the treatment group (A) speaking out an average of 2.37 comments more than at the beginning of the unit and the control group (B) increasing in mean number of comments by 3.18 (Table 3 ). 
Table 3: Verbal Participation Mean, SD, and t-test Results

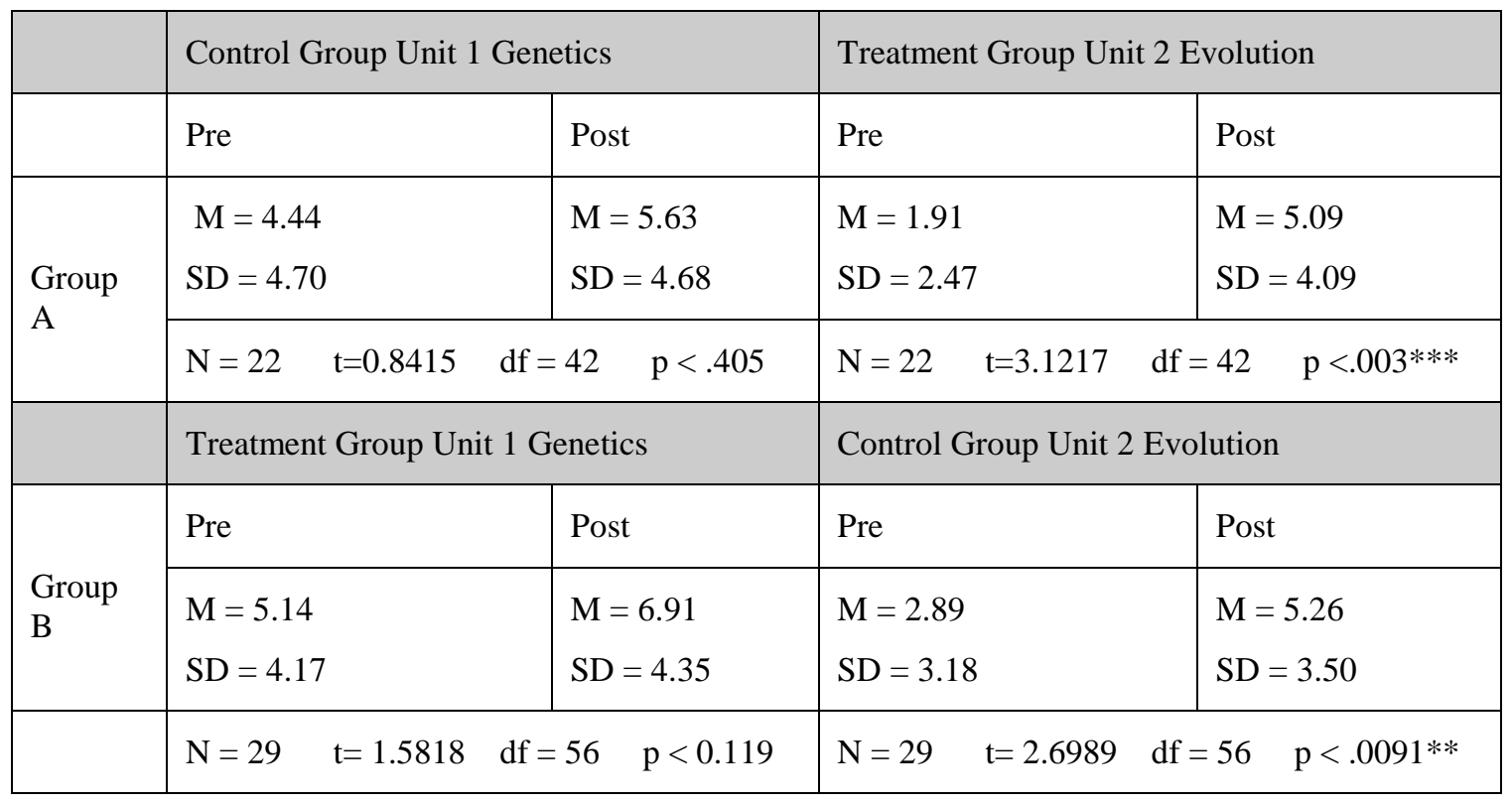

$* p<.05 \quad * * p<.01 \quad * * * p<.005$ 
Figures 3 and 4 present the mean number of comments made by each group in histogram format.

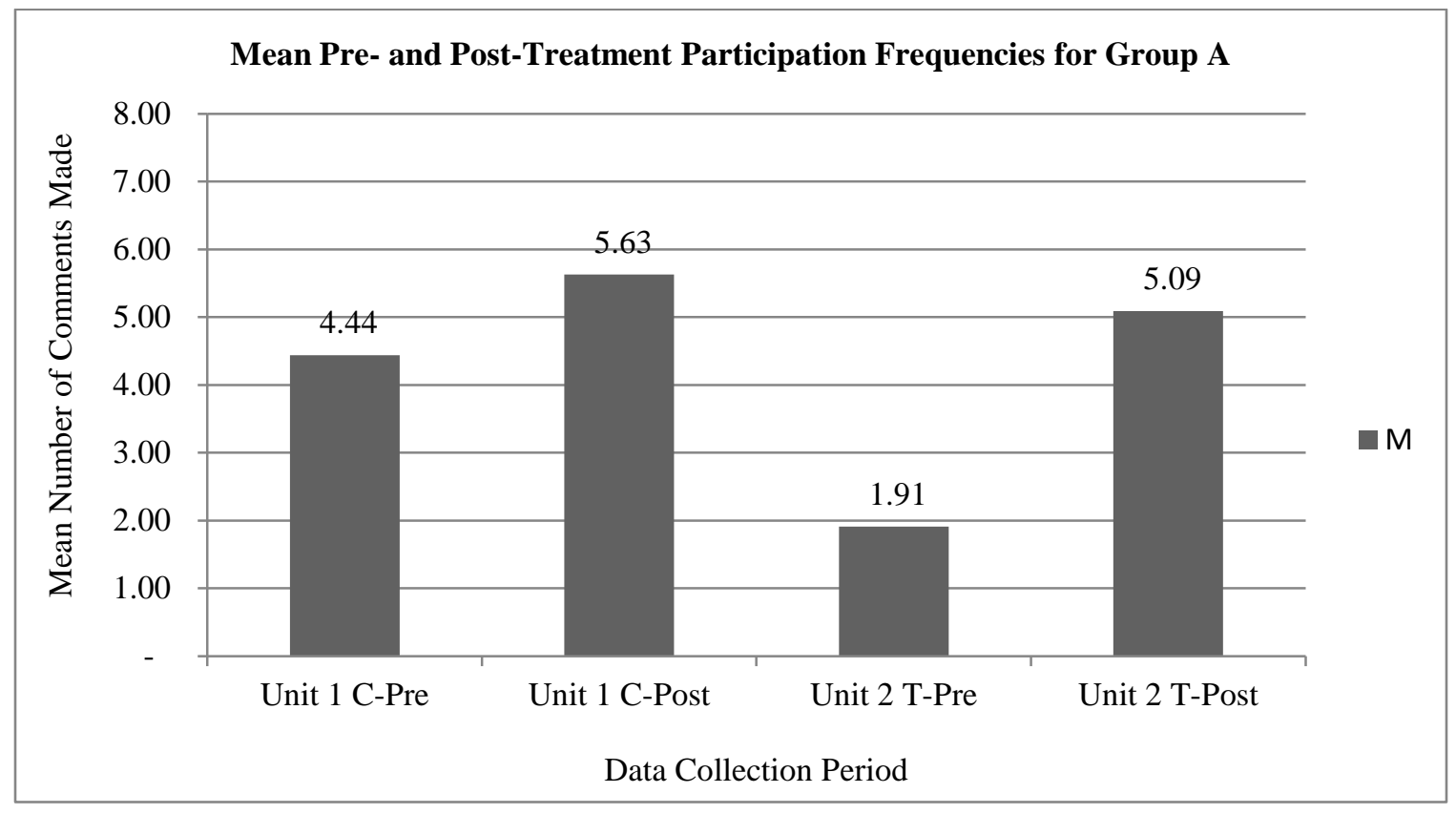

Figure 3: Histogram of mean pre- and post-treatment participation frequency for Group A

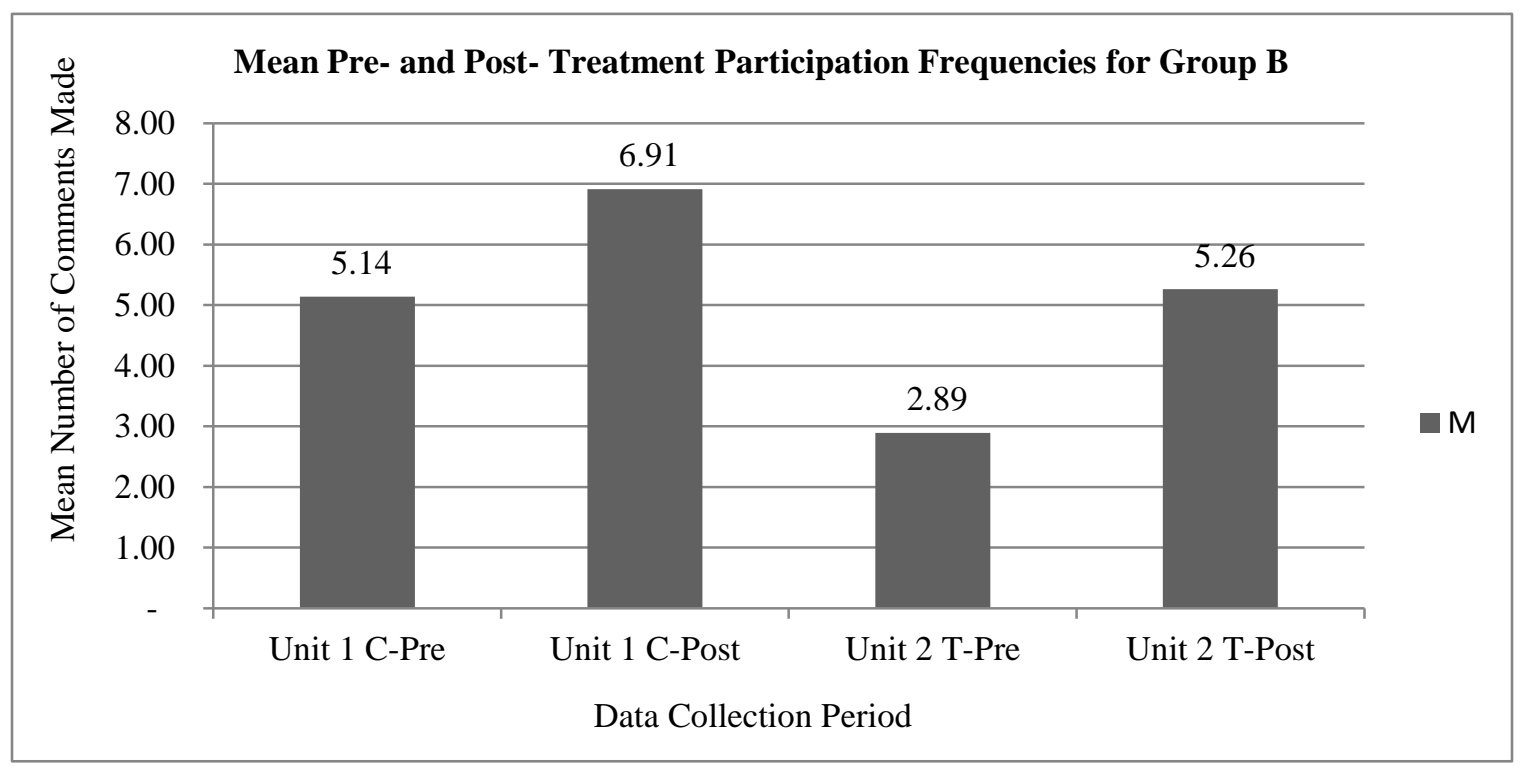

Figure 4: Histogram of mean pre- and post-treatment participation frequency for Group B 
Inferential statistical analysis of the gains in student verbal participation for both instructional units and subject groups were also calculated (Table 3). For each group receiving the intervention instruction in vocabulary learning strategies and pronunciation, student gains in verbal participation in class increased, as measured by the mean frequency of comments made, although only significantly for Group A in Unit 2, $t(42)=$ 3.1217, $p<0.003$. Variation was found in the control groups for each unit, with insignificant gains in participation pre- and post-intervention in Unit $1, t(42)=0.8415, p$ $<4.05$, while the Group B, those who had received the pronunciation in the first unit, but not the second, had an significant increase in the mean number of comments made during class, $t(46)=2.6989, p<0.0091$.

\section{Gains in the Verbal Use of Scientific Vocabulary}

The quality of student comments made during class discussions was tracked and scored using the Student Use of Scientific Vocabulary instrument (Appendix A). Each student comment was scored with a $0,1,2$, or 3 signifying the relevance of the statement to the class discussion and the use of a pre-determined vocabulary word from the biology unit (Appendix C). The Comment Ranking Scale can be seen in Figure 5.

$0=$ no content related comments are made (ex. Can I go to the restroom?)

$1=$ content is referenced, but without using a vocabulary word (ex. Water goes through the membrane)

2 = vocabulary word is used, context is inaccurate (ex. Osmosis is when water and solute concentrations are equal)

3 = vocabulary word and context are correct (ex. Osmosis is when water passes through a semi-permeable membrane, going from an area of low to high solute concentration)

Figure 5: Comment ranking scale 
All comments were ranked during collection of participation frequency data to assess potential increases in the verbal use of scientific vocabulary words. Comments where a vocabulary word is used are combined and ranked as "high value" for the purpose of this study, as accuracy is not being assessed in this study, only the attempted oral usage of vocabulary words. Student data from both units of instruction is combined in the following analyses due to the novelty of each vocabulary set at the beginning of each unit. Groups A and B began each unit with no prior exposure to the terms to be used, as opposed to the quantitative participation data, where Group B had prior exposure the intervention. The following series of charts and tables summarize the inferential and descriptive analyses of comment types pre- and post-intervention for both treatment and control groups, combining data from both units.

Table 4: Descriptive statistics for the frequency of student comment types

\begin{tabular}{|l|l|l|l|l|l|l|l|l|}
\cline { 2 - 8 } \multicolumn{1}{c|}{} & $\begin{array}{l}\text { Pre- } \\
\text { Total } \\
\text { Ranking } \\
0-1\end{array}$ & $\begin{array}{l}\text { Post- } \\
\text { Total } \\
\text { Ranking } \\
0-1\end{array}$ & $\begin{array}{l}\text { Post- } \\
\text { Mean } \\
\text { Ranking } \\
\mathbf{0 - 1}\end{array}$ & SD & $\begin{array}{l}\text { Pre- } \\
\text { Total } \\
\text { Ranking } \\
2-3\end{array}$ & $\begin{array}{l}\text { Post- } \\
\text { Total } \\
\text { Ranking } \\
2-3\end{array}$ & $\begin{array}{l}\text { Post- } \\
\text { Mean } \\
\text { Ranking } \\
\mathbf{2 - 3}\end{array}$ & SD \\
\begin{tabular}{|l} 
Control \\
Groups
\end{tabular} & 62.00 & 162.00 & $\mathbf{3 . 3 1}$ & 2.80 & 100.00 & 102.00 & $\mathbf{2 . 0 8}$ & 2.35 \\
\hline $\begin{array}{l}\text { Treatment } \\
\text { Groups }\end{array}$ & 86.00 & 146.00 & $\mathbf{2 . 9 8}$ & 1.94 & 105.00 & 148.00 & $\mathbf{3 . 0 2}$ & 2.55 \\
\hline
\end{tabular}

Note: Rankings of 0 and 1 are combined to represent comments made without the implementation of a unit vocabulary word; rankings of 2 and 3 are combined to represent comments made with the implementation of a unit vocabulary word; SD standard deviation

Table 4 illustrates the frequency distributions and central tendencies for the control and treatment groups pre- and post-intervention. Control and treatment groups 
both had a higher frequency of low value (0-1) comments after the intervention units, while those students who received instruction in pronunciation and vocabulary learning strategies combined (intervention), resulted in a lower mean use of low quality comments, $\mathrm{M}=2.98<\mathrm{M}=3.31$. The total number of high value (2-3) comments after the intervention time period increased in frequency by 2 for the control groups and by 43 comments for the treatment groups. Students receiving the treatment lessons used a low quality comment an average of 2.98 times during class and a high quality comment 3.02 times. The mean frequency of comments using scientific terminology varied from 2.08 for the control students to 3.02 for the treatment classes. The histogram seen in Figure 6 shows the frequency of each student comment type before and after the pronunciation intervention. 


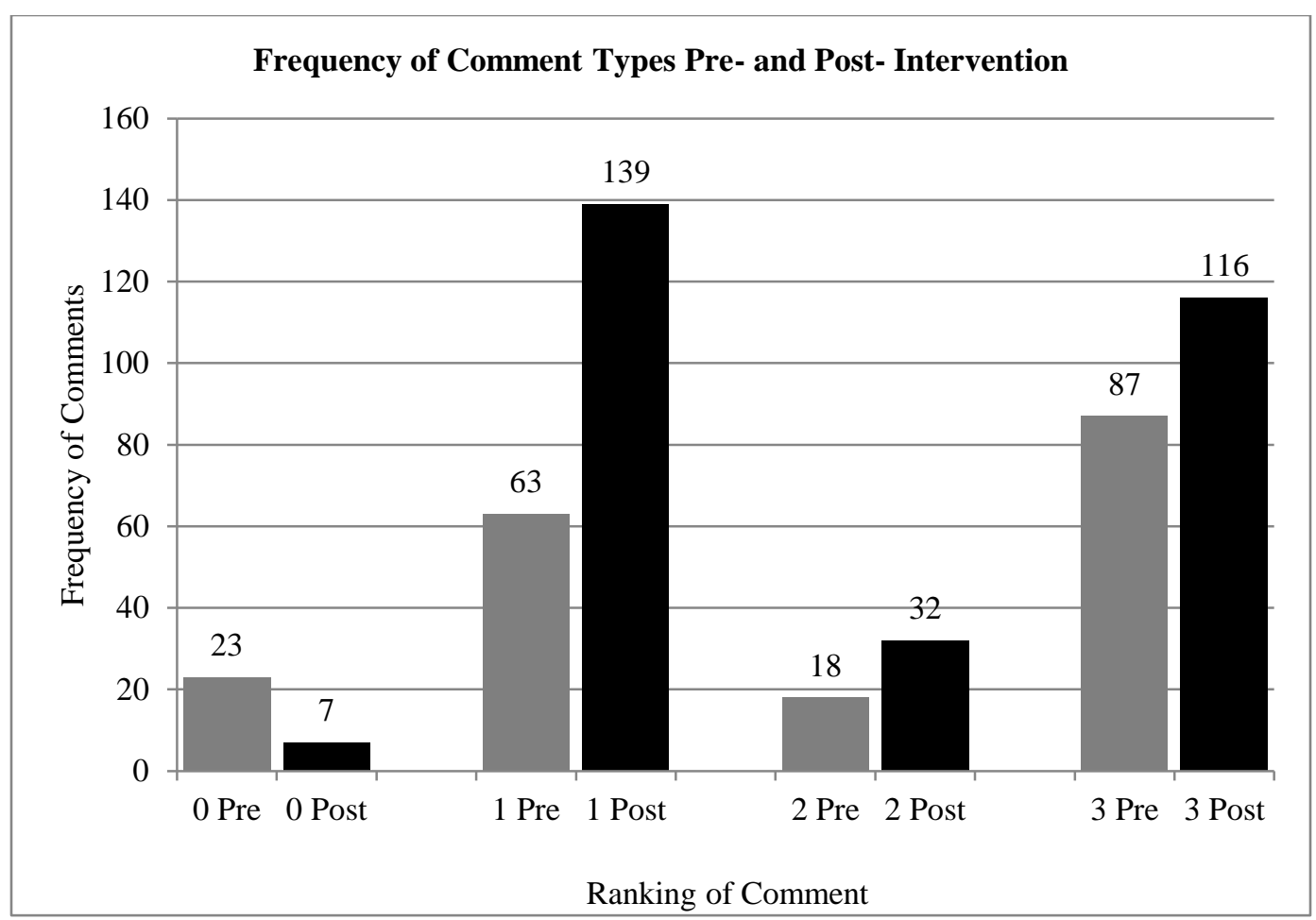

Figure 6: Histogram of the frequency of comment types pre-and post-intervention

Using an unpaired t-test, a significant effect was calculated between the control and treatment groups' mean number of high value (rank: 2-3) comments, $t(96)=1.87$, $p=0.0320$, after the intervention. A significant effect was also calculated for pre- and post- intervention comparisons within the treatment group, $t(96)=1.69, p=0.0475$, for the mean frequency of high value comments. The results of these inferential statistics can be seen in Table 5. 
Table 5: T-tests for statistical significance in mean frequency of student comments using vocabulary terms

\begin{tabular}{|l|l|l|l|l|}
\cline { 2 - 5 } \multicolumn{1}{c|}{} & $\boldsymbol{t}$ Value & $\begin{array}{l}\text { Degrees of } \\
\text { Freedom }\end{array}$ & $\boldsymbol{p}$ Value & $\begin{array}{l}\text { Statistical } \\
\text { Significance }\end{array}$ \\
\hline $\begin{array}{l}\text { Control v. Treatment Units: Post- } \\
\text { Intervention Mean Frequency of High } \\
\text { Value Comments }\end{array}$ & 1.87 & 96 & 0.0320 & Significant \\
\hline $\begin{array}{l}\text { Treatment Units: Pre- v. Post- } \\
\text { Intervention Mean Frequency of High } \\
\text { Value Comments }\end{array}$ & 1.69 & 96 & 0.0475 & Significant \\
\hline
\end{tabular}

An additional analysis of high value (2-3) comments, pre- and post-intervention, for the treatment groups is shown through a two-variable linear model in Figure 7. This correlational scatterplot shows an increase in the verbal use of vocabulary words for students after receiving the intervention, with increases being relational to a students' pre-intervention use of vocabulary words aloud in class. The two values, pre- and postintervention frequency of vocabulary use, were strongly correlated, $r(47)=.45, p<$ 0.001 .

Gains in the quality of student comments, measured by the presence or absence of vocabulary words, were calculated by determining the difference in modes of ranked comments for each student before and after exposure to the intervention strategies. A slightly positive correlation, $r(47)=0.17, p=0.242$, was calculated between gains in student verbal participation in class discussions and gains in the use of scientific vocabulary terms post-intervention. 


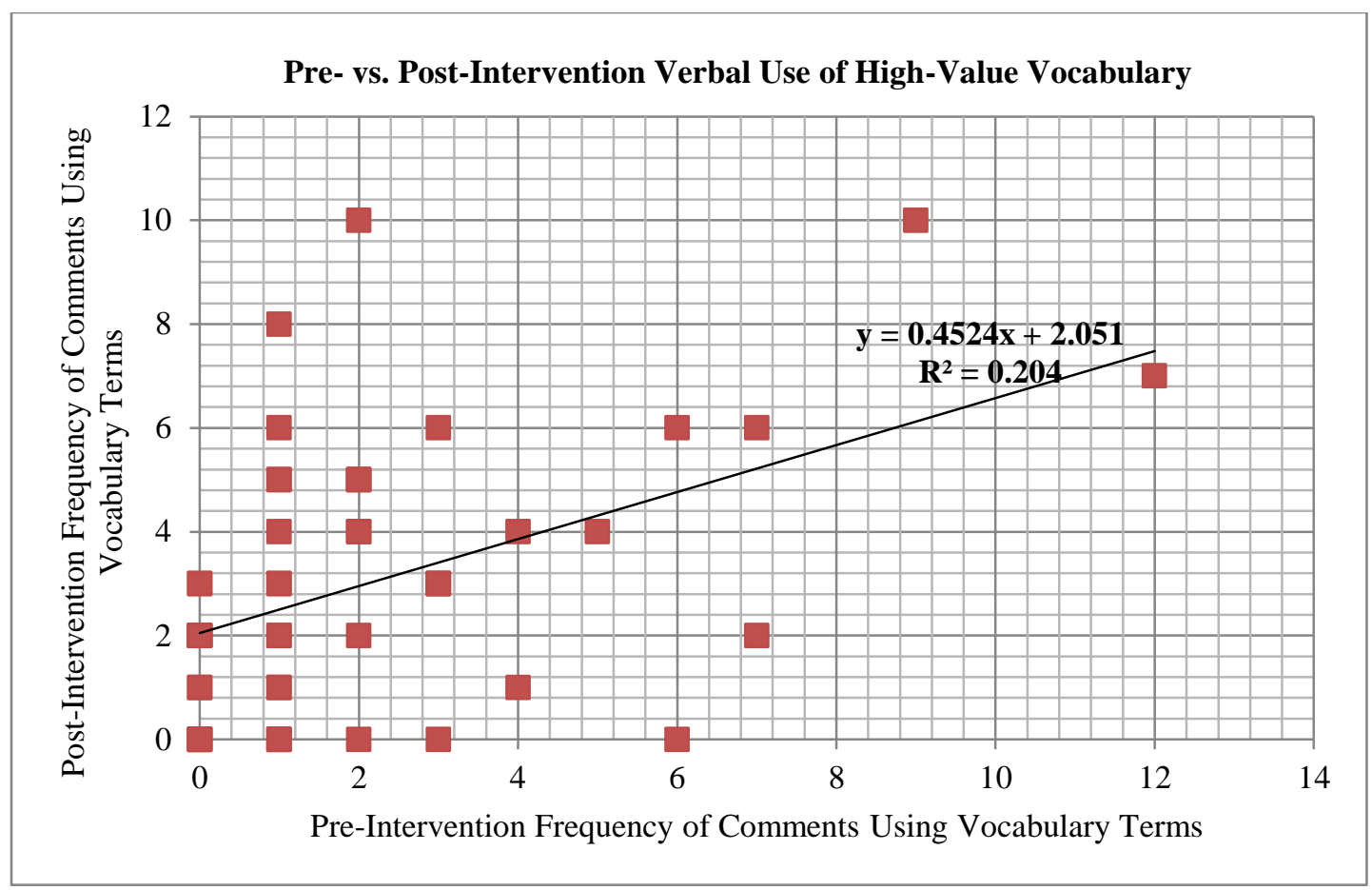

Figure 7: Linear model with correlation coefficient for pre- and post-intervention verbal use of high value vocabulary

Correlations between Student Participation Gains and Survey Responses

All participants were given the Survey of Self-Efficacy in Scientific Discourse (Appendix B), with a combination of Likert scale and open-ended questions to assess their own confidence and abilities in scientific verbal communication skills pre- and postintervention. The responses selected questions were analyzed for central tendencies and correlations with measured gains in class participation and the verbal use of related vocabulary terms. This qualitative data was also quantified to evaluate student perceptions of the usefulness of specific intervention strategies in the development of their scientific discourse skills. 
Table 6 presents the frequency distributions of coded responses to open-ended survey question 7, addressing the factors that students' perceive to influence their decision to speak in class. Over $80 \%$ of all students, $n=49$, expressed their confidence in having a correct answer or idea as the primary influence in their decision to speak. Over half of all students, $65.22 \%$, stated that the dynamics of the class as a whole impact their decision to verbally participate. These factors included a student's comfort with speaking in front of the group and whether or not anyone else raised their hand to answer. A small percentage of students recorded that the number of opportunities presented for discussion by the teacher impacted their decision to speak. 
Table 6: Responses to survey question 7

\begin{tabular}{|c|c|c|c|}
\hline Question & Themes & $\begin{array}{l}\text { \% of Students } \\
\text { Expressing } \\
\text { Theme }\end{array}$ & Sample Quotations \\
\hline \multirow[t]{3}{*}{$\begin{array}{l}\text { 7. If you often speak in large } \\
\text { group discussions in science } \\
\text { class (asking a question, } \\
\text { answering a question, } \\
\text { sharing your homework } \\
\text { solutions with the whole } \\
\text { class, etc.), what influences } \\
\text { your decision to speak? }\end{array}$} & $\begin{array}{l}\text { Statements of } \\
\text { Confidence in } \\
\text { Correctness }\end{array}$ & 80.43 & $\begin{array}{l}\text { "if I know I'm right", } \\
\text { "I'm afraid of being } \\
\text { wrong", "I know the } \\
\text { answer", "embarrassing } \\
\text { myself if I'm wrong", } \\
\text { "comfortable with the } \\
\text { topic", "100\% sure I'm } \\
\text { right"' }\end{array}$ \\
\hline & $\begin{array}{l}\text { Statements of Comfort } \\
\text { with the Group or } \\
\text { Group Dynamics }\end{array}$ & 65.22 & $\begin{array}{l}\text { "I only answer if no one } \\
\text { else raises their hand", } \\
\text { "to get the discussion } \\
\text { rolling", "when others } \\
\text { are speaking", "wanted } \\
\text { to express my opinion", } \\
\text { "I don't like large } \\
\text { groups", "I'm not in an } \\
\text { immature classroom" }\end{array}$ \\
\hline & $\begin{array}{l}\text { Statements of Having } \\
\text { Opportunity and Time } \\
\text { to Speak }\end{array}$ & 15.21 & $\begin{array}{l}\text { "I spoke more because } \\
\text { I had a lot of } \\
\text { opportunities", "I got } \\
\text { called on", "need time } \\
\text { to think" }\end{array}$ \\
\hline
\end{tabular}

Note: Total percentage exceeds $100 \%$ due to multiple thematic responses from students

Survey Question 9 addressed student perceptions of the role of learning pronunciation in their verbal participation in science class discussions. The preintervention question asked students if they thought learning pronunciation would affect their participation and why or why not; the post-intervention question asked if the treatment did affect their participation and why or why not. Table 7 presents student responses to the pre- and post-intervention question, the frequency distribution of 
changes in perception, and sample responses addressing why or why not pronunciation affects student verbal participation in scientific discourse. Twenty-eight percent, $n=13$, of students did not initially expect instruction in pronunciation to impact their participation in class discussions, but cited a positive change post-intervention. One-third of students expressed that learning pronunciation built their confidence in their own ability to use scientific terminology orally and one-third expressed that learning pronunciation increased their understanding of the vocabulary. Over half of students stated and additional variable that impacted their participation in class such as a lack of concern with proper pronunciation or a dislike of public speaking regardless of their comfort with terminology. 
Table 7: Responses to survey question 9

\begin{tabular}{|c|c|c|c|c|c|}
\hline Question & $\begin{array}{l}\text { Pre- } \\
\text { "Yes" } \\
\text { Response }\end{array}$ & $\begin{array}{l}\text { Post- } \\
\text { "Yes" } \\
\text { Response }\end{array}$ & Themes & $\begin{array}{l}\% \text { of } \\
\text { Students } \\
\text { Expressing } \\
\text { Theme }\end{array}$ & Sample Quotations \\
\hline \multirow[t]{3}{*}{$\begin{array}{l}\text { 9. Would/did learning } \\
\text { and practicing how to } \\
\text { pronounce scientific } \\
\text { vocabulary words effect } \\
\text { your participation in } \\
\text { class discussions? Why } \\
\text { or why not? }\end{array}$} & $24.49 \%$ & $38.78 \%$ & $\begin{array}{l}\text { Statements } \\
\text { of } \\
\text { Confidence } \\
\text { Building }\end{array}$ & $32.61 \%$ & $\begin{array}{l}\text { "got me to say it } \\
\text { with confidence", } \\
\text { "everyone got to } \\
\text { learn how to say } \\
\text { them without being } \\
\text { embarrassed", } \\
\text { "gave me more } \\
\text { confidence", } \\
\text { "helped with the } \\
\text { ridiculously long } \\
\text { words", "more } \\
\text { comfortable sharing } \\
\text { the vocabulary" }\end{array}$ \\
\hline & & & $\begin{array}{l}\text { Statements } \\
\text { of Increased } \\
\text { Understandi } \\
\text { ng of } \\
\text { Definitions }\end{array}$ & $32.61 \%$ & $\begin{array}{l}\text { "it left a memory } \\
\text { imprint", "helped } \\
\text { with definitions", } \\
\text { "it made } \\
\text { connections", } \\
\text { "clearer } \\
\text { understanding" }\end{array}$ \\
\hline & & & $\begin{array}{l}\text { Statements } \\
\text { of External } \\
\text { Variables } \\
\text { that Impact } \\
\text { Verbal } \\
\text { Participation }\end{array}$ & $56.52 \%$ & $\begin{array}{l}\text { "I just don't like } \\
\text { public speaking", I } \\
\text { don't care if I } \\
\text { mispronounce a } \\
\text { word", "I don't } \\
\text { have problems } \\
\text { pronouncing } \\
\text { words", }\end{array}$ \\
\hline
\end{tabular}

Five instructional strategies were used in the intervention to develop vocabulary and reinforce skills pertaining to oral communication: using Frayer-model flashcards, learning vocabulary with technology through www.dictionary.com, jig-saw read alouds, creative writing tasks, and playing whole-class review games. Question 8 of the survey 
asked students to identify strategies that most and least helped them to learn and use science vocabulary. Table 8 shows the perceived usefulness of each instructional strategy by students.

Table 8: Most and least helpful instructional strategies for learning scientific vocabulary, as reported by Students, post-intervention

\begin{tabular}{lccl}
\hline \multicolumn{1}{c}{ Strategy } & $\begin{array}{c}\text { \% of Students Citing as } \\
\text { "Most Helpful" } \mathrm{n}=49\end{array}$ & $\begin{array}{c}\text { \% of Students Citing as } \\
\text { "Least Helpful" } \mathrm{n}=49\end{array}$ & $\begin{array}{l}\text { Mean Increase in } \\
\text { Participation by } \\
\text { number of comments }\end{array}$ \\
\hline $\begin{array}{l}\text { Whole-Class Review } \\
\text { Games }\end{array}$ & $34.69 \%$ & $2.04 \%$ & 2.41 \\
$\begin{array}{l}\text { Frayer-Model } \\
\text { Flashcards }\end{array}$ & $32.65 \%$ & $18.37 \%$ & 1.69 \\
Dictionary.com & $14.29 \%$ & $6.12 \%$ & 2.14 \\
Other & $18.36 \%$ & $73.47 \%$ & 3.20 \\
& & & \\
\hline
\end{tabular}

Mean increases in participation were measured by calculating the average of the difference in number of oral comments made by each student pre- and post-treatment. Review games and flashcards were the most useful instructional strategies reported by students (Table 8), while only one student out of 49 found jig-saw style read-alouds to be helpful in their acquisition and oral use of vocabulary terms. The students that cited Frayer-Model Flashcards as the most helpful strategy in learning vocabulary had a mean increase in participation of 1.69 comments after the treatment. Students who reported whole-class review games as the most helpful tool in learning vocabulary had the greatest mean increase in participation at a rate of 2.41 more comments post-intervention than pre-intervention. 


\section{Interview Results}

Interviews were conducted after both study groups had received the treatment intervention. Students were randomly selected to be interviewed after being dividing into two groups based on their responses to survey question 9, addressing their perception of the role of learning pronunciation in their verbal classroom participation; those participants who claimed that pronunciation instruction did impact how often they spoke in class and those who claimed it had no effect. Three students were chosen from each sub-group for questioning. Interviews took place during regular school hours and lasted for 10-15 minutes each. The following quotations represent the most common themes presented from student responses.

Question 1: Do you speak often in class? What influences your decision to speak? What could make you speak more?

Responses: "I speak a lot, but only if I know the answer and I'm comfortable with the class." "I usually wait for somebody else to talk who can explain it better." "I don't speak a lot because I'm afraid of being wrong or making a mistake in how I say things." "I don't usually say big words because I don't fully understand what they mean."

Although phrased in individual ways, each interview subject broached the theme of confidence in their understanding and knowledge as primary inhibitors of their verbal participation in class. Students expressed concerns about being incorrect and making a mistake regarding content or language in front of their peers. 
Question 2: In the last two units, genetics and evolution, we used five different ways to practice vocabulary: flashcards, dictionary.com, letter writing, reading the textbook in groups, and playing review games. Which of these helped you learn the words the most? Which helped the least?

Responses: "Using dictionary.com gave me quick definitions of words." "I used dictionary.com to help me make flashcards." "Flashcards let me practice the words many times." "Flashcards were really helpful to use before the review game."

Similarly reflecting the survey responses, Frayer-model flashcards, Dictionary.com, and playing Whole-class review games were deemed by students as the most helpful strategies for learning vocabulary. The interviews revealed students' initiative to use these three methods in conjunction with one another as a study method.

Question 3: When do you use "science words" instead of just a description? What helps you use the vocabulary word instead?

Responses: "When I hear other people use that word." "When I know I can pronounce it correctly." "When I really understand the definition."

Students stated that in order to use a "science word", such as "pedigree", instead of "the family tree", they needed to have confidence in their understanding of the word and also have repeated auditory exposure to the term from their teachers and peers. Two of the six students interviewed mentioned the need to pronounce a word comfortably before they would say it aloud. 
Question 4: Did learning and practicing how to pronounce scientific vocabulary words effect your participation in class discussions? Why or why not?

Responses: "Yes, I felt more comfortable and it helped my thought go easier." "Yes, reviewing was a lot more fun and easier because we knew the words." "No, I don't mind if I mispronounce words, but I'm glad we got to try and attempt them correctly." "No, I still need to know the definition well to use it aloud."

Participants in the interviews mimicked their survey responses by declaring that pronunciation instruction either led them so speak more in class due to an increased confidence level or did not affect their verbal participation due to inherent confidence or persistent challenges in understanding definitions. Over half of interview participants stated that pronunciation instruction was enjoyable regardless of its impact on participation.

Question 5: Did learning how to pronounce vocabulary words help you learn or remember the meaning of those words?

Responses: "Repeating the words a lot helped." "Learning the stems and Latin roots was helpful." "It was fun to guess the meaning from the roots first; that helped me remember." "No, pronunciation didn't help me remember the meaning, but it helped me say it correctly." "It helped my ability to use it in class."

Students expressed benefits to learning word definitions from the instructional strategy used on the first day of each unit, where common Greek and Latin word stems were introduced. Repetition was also cited as common theme to assist in learning vocabulary definitions. Two students re-stated the positive effects of pronunciation instruction on their verbal participation in class, but did not find the strategy useful for learning word meanings. 


\section{CHAPTER 5: DISCUSSION}

\section{Interpretation of Findings}

This study was designed to answer the research question: can the frequency and propensity of student participation in class discussion be increased by instruction in the pronunciation of scientific vocabulary? To analyze these findings the question is divided into two parts: did the quantity of student verbal participation increase post-intervention and did the quality of student participation increase after explicit instruction in pronunciation?

Data results from the quantitative measures of participation gains were intended to compare how students in the control group fared compared to those who received pronunciation in instruction after the completion of one curricular unit. Differences in the mean number of comments made before and after the intervention were also analyzed within each student group. At the end of the first unit of instruction, using a genetics curriculum, the Group B had a higher gain in the mean number of comments made per student (1.77) than Group A (1.19), though this difference was not significantly significant. After the second unit, using an evolution curriculum, Group A showed greater gains in participation frequency (mean gains of 3.18 comments per student), than the Group B (mean gains of 2.37 comments per student), who received the control instruction. This continued increase in participation for the group of students who participated in the intervention during the first unit may reflect the lasting effects of increased verbal participation in classroom discussions. While both groups showed increases in participation from pre- to post-intervention within each unit, only treatment 
Group A made statistically significant gains. Significant gains in Group B were detected in the unit after their exposure to the treatment, but not within. This increase does reflect the effectiveness of engaged vocabulary strategies with explicit pronunciation instruction on students' verbal participations.

The initial and follow-up survey was developed to measure the degree of change in students' perception of their ability to communicate orally in class (Curto \& Bayer, 2005). Results of survey and interview questions regarding students' perceptions of pronunciation instruction on their verbal participation showed nearly $39 \%$ of students claiming that instruction in pronunciation increased their participation in class. Nearly $33 \%$ of students reported on surveys that learning how to pronounce words in class built their confidence. These findings suggest that student confidence and self-efficacy is linked to their propensity to speak aloud in class and that teachers can minimize inhibitions for many students through repeated pronunciation instruction.

Findings regarding changes in the quality of student comments made after a unit of instruction with emphasis on vocabulary pronunciation were also assessed both qualitative and quantitatively. The control groups for each unit made slightly more comments in class that did not incorporate a vocabulary word (3.31 comments per student) than the treatment groups (2.98 comments per student). Students who received the intervention instruction had a statistically significant higher mean frequency of comments made using a vocabulary word (3.02 comments per student) than those in the control group (2.08 comments per student). After each student group received the pronunciation instruction, they had a significantly higher use of vocabulary words in their 
comments to the class than prior to the intervention. This increase in the mean number of vocabulary words used in classroom discussions after instruction in pronunciation suggests a significant improvement in students' efficacy to speak the language of science within the biology classroom.

Gains in student efficacy to use vocabulary words over generalized descriptive phrases were also found qualitatively though interview results. Interviewees stated that hearing vocabulary words repeatedly, learning how to pronounce them correctly and having a firm grasp of the definition all contributed to their use of those words in classroom conversations. The survey and interview results validated the positive effects of explicit and engaged instruction in verbal uses of vocabulary on the quality of student oral discourse in science.

Regarding the various intervention instructional strategies used in this study, qualitative feedback was analyzed through student interviews and surveys to determine the perceived effectiveness of five different literacy methodologies. Nearly $35 \%$ of students reported Whole-Class Review Games to be the most useful strategy in learning vocabulary words. This was followed closely by $32 \%$ of students citing Frayer-Model Flashcards as the most helpful for retaining information. Both of these strategies were designed to allow for repeated use of vocabulary words aloud and for social interaction. The popularity and perceived usefulness of these methods reflect the important role of oral communication and multiple opportunities for use when providing vocabulary instruction to students. During the intervention, students also worked in pairs to guess the meaning of vocabulary words based on the Latin word roots. They were then asked to 
share their hypothesis with the class. This activity was cited in surveys and interviews as both fun and useful to students for learning new words, further suggesting the importance of verbally interactive learning communities in the science classroom, where emphasis on language skills is embedded in the content.

\section{Conclusion}

Many of the findings of this research are consistent with the current literature studying the role of instruction and literacy strategies designed to further students' verbal participation and oral scientific communication skills in the classroom. To identify initial impediments to students' competence and confidence in oral communication skills, Smith and Sodano (2011) used post-presentation surveys to evaluate factors hampering students' self-efficacy in public speaking. The findings of the survey used in this study aligned with those of the aforementioned researchers, concluding that student's selfconfidence in their abilities to present science to their peers is lacking due to anxiety over proper pronunciation and accuracy of vocabulary and content. Self-perceived competency with content and vocabulary is a primary inhibitor for students. This study and that of Smith and Sodano (2011) and Dunn (1989) found students to report that methods bestsuited to assist them overcome these anxieties include practice and repetition of challenging words and using phonetic spellings. Dunn (1989) also proposed the use of expressive writing as a tool for students to reinforce correct applications of vocabulary, while the results of the student survey on this study found a preference for interactive 
games and the use of flashcards over writing assignments as vocabulary acquisition strategies. This discrepancy may be due to the college level academic mindset of Dunn's students, while the high school aged participants of this study show little desire for additional writing assignments, regardless of their potential benefits. Consistently found within the literature and supported by this study is the supposition that students must feel confident in their knowledge and phonetic abilities to voluntarily and successfully participate in scientific discourse in the classroom.

Post-treatment means in the frequency of participation were higher than pretreatment means for all groups (control and treatment) over both units. This increase in students' verbal participation levels reflected the benefits of general instruction in the concept topics regardless of instruction in pronunciation. Teaching evolution and genetics using methods that emphasize vocabulary instruction and incorporate literacy strategies provided students with multiple opportunities to become familiar enough with the concepts to be able to participate meaningfully in guided discussions about inheritance patterns and homologous structures. Interview results acknowledged the importance of content understanding as key factors in students' propensity to participate in concept discussions. Knowledge and comprehension were repeatedly cited in interviews and surveys as inhibitors or enhancers affecting students willingness to speak; much more so than confidence in pronunciation. The role of confidence in students' rates of verbal participation may not be sourced to affective states of emotional security as much as to students' desire for unquestionable comprehension of the material. 
The methods for instruction in pronunciation used in this study were embedded in the vocabulary learning and oral communication strategies suggested by Marzano's SixStep Process for Teaching New Terms (2004) and Murphy's Scale of Activities for Accuracy in Oral Communication by Proficiency Level (1991). Educators must use and often adapt the vocabulary instruction and scientific communication skills strategies that are best-suited for their unique classroom of diverse students. The findings of this research showed that the combination of established vocabulary and oral communication learning strategies contributed positively to student's verbal participation rates, the use of vocabulary words orally, and to $38 \%$ of students' self-efficacy in their ability to participate in biology discussions. By fusing activities, such as learning word stems with repeated phonetic break-downs of words, students in this study were given multiple opportunities to evaluate contextual meanings of vocabulary while developing oral literacy skills.

Numerous studies within the literature have demonstrated that improved scientific literacy can be attained after students have experiences with skills-based opportunities in oral communication skills. The findings of this research showed that students' verbal use of scientific vocabulary words increased after direct instruction and multiple opportunities for communication skill-building (pronunciation practice) compared to those students who did not receive this instruction. Spektor-Levy, Eylon \& Sherz (2009) developed and implemented an instructional program, "Scientific Communication" for 202 high school juniors to assess changes in oral presentation abilities after planned intervention. After two years of participation in that program, students who received 
explicit instruction in scientific communication skills demonstrated improved use of professional terminology compared to their peers in the comparison group. While this study occurred with a smaller sample size and over a period of months, instead of years, the results are congruent in establishing the need for explicit instruction in scientific communication skills as the quality of student verbal participation in class discussions has been found to correspondingly increase.

In conclusion, the qualitative results of this study are consistent with the literature regarding the positive effects of explicit vocabulary instruction on scientific literacy and student efficacy in oral communication skills, but are unique in the quantification of measurable gains in student verbal participation in classroom conversations as a result of those interventions. The implications of these findings for high school science educators support the need for literacy strategies that emphasize not just students' abilities to write and recite relevant vocabulary, but to use vocabulary methodologies that encourage the practices of verbal communication. Vocabulary instruction is most effective when teachers emphasize the need to use vocabulary words accurately to communicate competently and effectively with peers and the global community. Teachers can increase this level of rigorous discourse in the classroom by selectively choosing the words to be taught that are most relevant and interdisciplinary and by providing students with multiple opportunities to use the terminology in context and discussion. This study found that instructing students in the pronunciation of biology-based vocabulary reduced the frequency of uninvited silences and increased the level of engagement and robust scientific discourse in the classroom. 


\section{Limitations}

The purpose of this study was to examine the effectiveness of instruction in the pronunciation of multi-syllabic science terminology on students' verbal participation in educational settings. An initial assessment of this proposal was evaluated through the preceding data collection and analysis, but several limitations are discussed to consider the overarching implications of this study on teaching and student discourse in the science classroom.

The small, non-randomized sample size used in this study $(n=49)$ limits the generalizability of the findings to all science classrooms. The sample populations consisted of two intact biology classes and the researcher was not able to pre-select participants based on academic or scientific discourse related criteria. This small sample size may not be representative of larger student populations beyond this suburban Oregon high school.

Timing of data collection for participation rates served as a limitation for this study as well. Pre-treatment data collection for Unit 1 (Genetics) occurred at the end of a unit on Cellular Processes, when students were familiar enough with terms and concepts to demonstrate a high level of verbal participation and terminology use. Pre-treatment data collection for Unit 2 (Evolution) occurred at the beginning of that unit only. This discrepancy limits inter-unit comparisons. While vocabulary terms from any prior instructional unit were recorded and ranked to calculate changes in the verbal use of scientific terminology, equivalent comparisons of the frequency of participation for the 
two units may be unreliable due to varying levels of student familiarity with concepts at the start of each unit. Pre-treatment participation data should be collected at the end of unrelated units and post-treatment data collected at the conclusion of the intervention units for more accurate evaluation of statistically significant differences between pre- and post-treatment verbal participation rates.

Additionally, the validity of the instrument used to collect student participation data may be limited. The Student Participation and Use of Scientific Vocabulary data collection form was designed by this researcher and has not been validated by other studies. Reliability of the participation frequency tallies may also have limitations due to two instances where a substitute teacher collected data instead of the regular classroom teacher. Although the substitute was familiar with most of the students, this unplanned inter-rater reliability was not examined thoroughly for congruency with the established intra-rater reliability determined by repeated use of the instrument by the assigned teacher.

Student absences are likely to have had an effect on the outcomes of this study as well. Each study group had a high number of absences throughout each unit, resulting in a loss of exposure to the five treatment lessons and in the availability of these students to make verbal contributions to class discussions. The lack of pronunciation instruction due to absences poses a threat to the causal inferences possible in this study, as students with a high or low post-intervention participation rate may have missed multiple treatment lessons. Student absences during participation data collection sessions limited both the 
quantity of expected data and a fuller representation of individual student's propensity to speak during class discussions.

An additional limitation of this study is the different challenges and cognitive demand associated with the various vocabulary words chosen for each unit. Students may have had more or less confidence and levels of comprehension with one group of terms over another, impacting their propensity to use those words aloud. Although each vocabulary set was taught using the same literacy strategies, some words may have been more novel to students than others and increased or decreased related measurements of word use and overall participation in each instructional unit.

Finally, the content associated with each instructional unit may have inherently raised different levels of engagement amongst the students, limiting or increasing the flow of scientific discourse accordingly. Although the guided discussions planned for use during data collection sessions was designed to be consistent in length and cognitive challenge, certain content topics, such as the evolution of vestigial appendages in hominids, often garnered more questions and comments from students than the role of meiosis in forming heterozygous alleles in gametes. The variation of perceived applicability of curricular topics to student lives may have led to variation in verbal engagement and limits the reliability of these findings across units and between treatment and comparison groups. 


\section{Recommendations}

The integration of scientific literacy strategies into direct classroom instruction has been shown to increase students' abilities to communicate effectively, revealing an understanding of content knowledge. Carnine \& Carnine (2004) and Young (2005) both emphasized the need for explicit instructional time for teaching vocabulary to achieve measurable comprehension gains. This research did not evaluate assessment scores, but did find the explicit, mixed methods approach of vocabulary instruction to produce higher frequency and quality of student participation. While this study was not designed to measure content knowledge or increased academic achievement, it provides evidence that prescribed, direct instruction in pronunciation, an important component of proficient oral discourse, can result in increased use of scientific language by students in the classroom, revealing comprehension of content. Further studies should be designed to gather evidence addressing the limitations of this study pertaining to growth in academic achievement corresponding to vocabulary instruction emphasizing pronunciation.

Expansion of this study to compare the results on a larger scale may further support these claims. It is suggested that additional research should compare results after using the same vocabulary set and pronunciation methodologies across multiple classrooms simultaneously, preferably across schools and geographic regions to account for limitations in demographic diversity and variation stemming from the cognitive demands of different curricular units. Additional learning and teaching methodologies should also be developed and assessed to improve strategies for pronunciation instruction in the classroom. 
This research shows promise to create a more engaging classroom environment, but does not address discrepancies in student participation based on demographics. Additional studies should be designed to evaluate differences in frequency of oral scientific discourse based on differences in demographics outside of the scope of this research. Gender, socio-economics, ethnicity, and exceptional learner status may all be contributing factors to students propensity and self-efficacy in oral vocabulary usage and verbal contributions to classroom discussions that are worthy of further analysis. 


\section{REFERENCES}

Alozie, N. M., Moje, E. B., \& Krajcik, J. S. (2010). An analysis of the supports and constraints for scientific discussion in high school project-based science. Science Education, 94(3), 395-427.

Ayers, D. M. (1972). Bioscientific terminology: words from Latin and Greek stems. Tucson: University of Arizona Press.

Carnine, L., \& Carnine, D. (2004). The interaction of reading skills and science content knowledge when teaching struggling secondary students. Reading \& Writing Quarterly, 20, 203-218.

Crawford, T. (2005). What counts as knowing: constructing a communicative repertoire for student demonstration of knowledge in science. Journal of Research in Science Teaching, 42(2), 139-165.

Curto, K. \& Bayer, T. (2005. Writing \& speaking to learn biology: an intersection of critical thinking and communication skills. Bioscene, 31(4), 11-19.

Dunn, J. R. (1989). How-to-do-it: are pronunciation exams effective in developing biology students' vocabulary? The American Biology Teacher, 51(3), 176-178.

Fisher, D. (2007). Creating a schoolwide vocabulary initiative in an urban high school. Journal of Education for Students Placed at Risk, 12(3), 337-351.

Groves, F. H. (1995). Science vocabulary load of selected secondary science textbooks. School Science and Mathematics, 95(5), 231-35. 
Krajcik, J.S., \& Sutherland, L.M. (2010). Supporting students in developing literacy in science. Science, 328, 456-459.

Marzano, R. J. (2004). Building background knowledge for academic achievement: research on what works in schools. Alexandria, VA: Association for Supervision and Curriculum Development.

Miller, J. (2005). The language of science is in daily conversation. Science Activities: Classroom Projects and Curriculum Ideas, 42(2), 3-4.

Milligan, J. L., \& Orlich, D. C. (1981). A linguistic approach to learning science vocabulary. Science Teacher, 48(2), 34-35.

Murphy, J. (1991). Oral communication in TESOL: integrating speaking, listening, and pronunciation. TESOL Quarterly, 25(1), 51-75.

National Research Council (U.S.). (2011). A framework for K-12 science education: practices, crosscutting concepts, and core ideas. Washington, D.C: National Academies Press.

Smith, C. M., \& Sodano, T.M. (2011). Integrating lecture capture as a teaching strategy to improve student presentation skills through self-assessment. Active Learning in Higher Education, 12(3), 151-162.

Spektor-Levy, O., Eylon, B.-S., \& Scherz, Z. (2009). Teaching scientific communication skills in science studies: Does it make a difference? International Journal of Science and Mathematics Education, 7, 875-903. 
Stahl, S. A., \& Fairbanks, M. M. (1986). The effects of vocabulary instruction: a modelbased meta-analysis. Review of Educational Research, 56 (1), 72-110.

Townsend, D. R., Filippini, A., Collins, P. \& Biancarosa, G. (2012). Evidence for the importance of academic word knowledge for the academic achievement of diverse middle school students. The Elementary School Journal, 112(3), 000 (article consists of 22 pages) ahead of print.

Trochim, W. M. (2006). Analysis. The research methods knowledge base. $2^{\text {nd }}$ edition. Retrieved from http://www.socialresearchmethods.net/kb/

Young, E. (2005). The language of science, the language of students: bridging the gap with engaged learning vocabulary strategies. Science Activities, 42(2), 12-17.

Wilson, M. (1998). Identifying and teaching essential science vocabulary. School Science Review, 80(291), 63-66.

Zohar, A., \& Nemet, F. (2002). Fostering students' knowledge and argumentation skills through dilemmas in human genetics. Journal of Research in Science Teaching, 39(1), 35-62. 


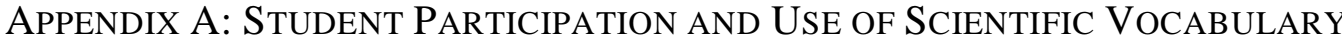 DATA COLLECTION FORM}

Observer Name:

Start Time:

Pre-Treatment or Post-Treatment (circle one)
Date: Study Group:

Control or Experimental (circle one)

\section{Comment Ranking Scale:}

$0=$ no content related comments are made (ex. Can I go to the restroom?)

$1=$ content is referenced, but without using a vocabulary word (ex. Water goes through the membrane)

$2=$ vocabulary word is used, context is inaccurate (ex. Osmosis is when water and solute concentrations are equal)

3 = vocabulary word and context are correct (ex. Osmosis is when water passes through a semi-permeable membrane, going from an area of low to high solute concentration)

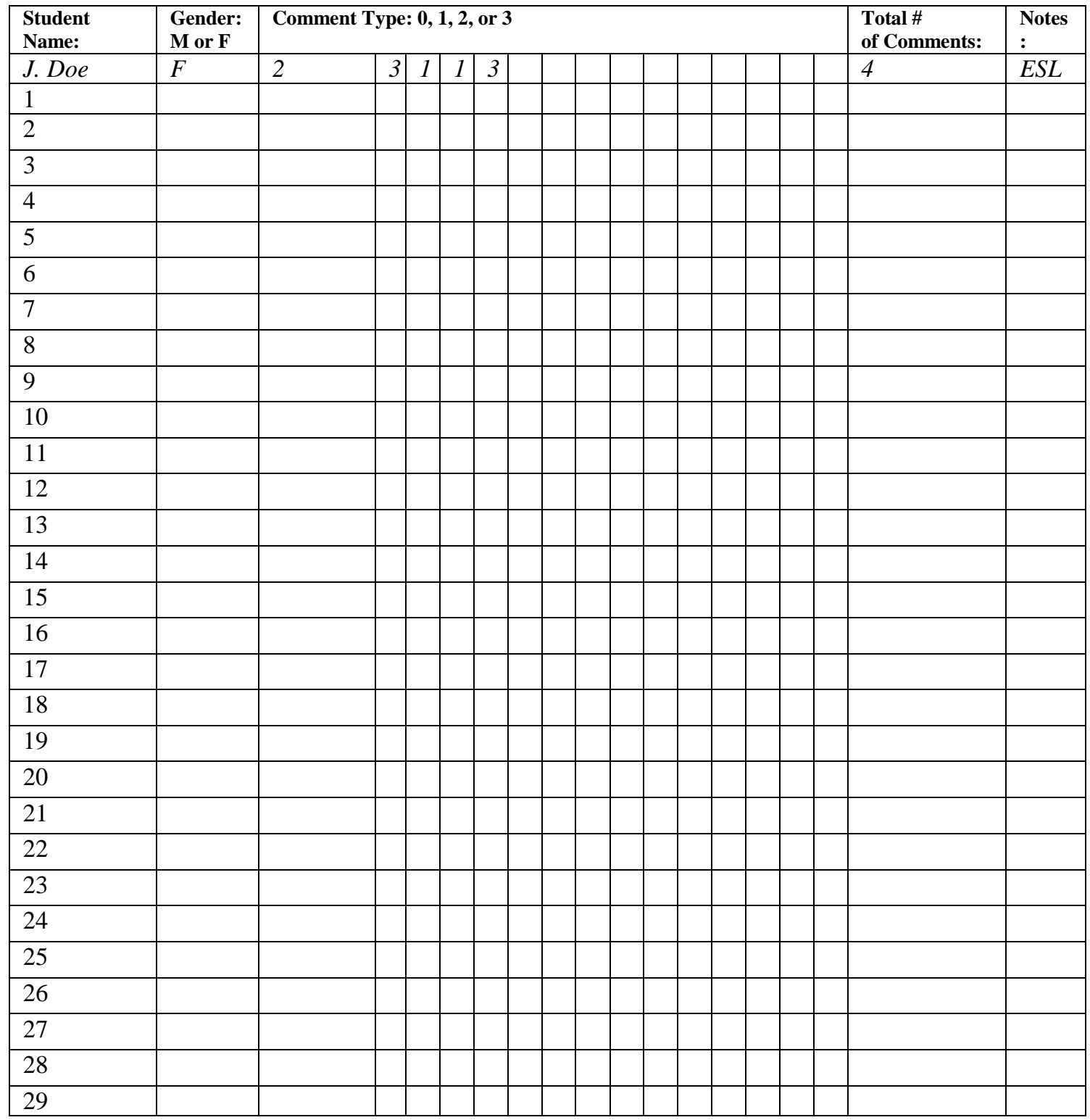




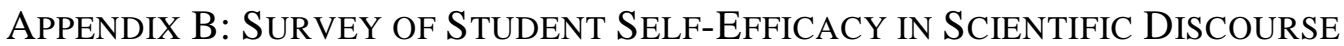

\begin{tabular}{|c|c|c|c|c|c|}
\hline & $\begin{array}{l}\text { Strongly } \\
\text { Agree }\end{array}$ & Agree & $\begin{array}{l}\text { Neither } \\
\text { Agree nor } \\
\text { Disagree }\end{array}$ & Disagree & $\begin{array}{l}\text { Strongly } \\
\text { Disagree }\end{array}$ \\
\hline $\begin{array}{l}\text { 1. I am comfortable speaking in front of } \\
\text { a small or large class group. }\end{array}$ & 1 & 2 & 3 & 4 & 5 \\
\hline $\begin{array}{l}\text { 2. I am able to communicate my } \\
\text { thoughts easily in front of a small or } \\
\text { large class group. }\end{array}$ & 1 & 2 & 3 & 4 & 5 \\
\hline $\begin{array}{l}\text { 3. It is difficult for me to find the right } \\
\text { words to express my thoughts in } \\
\text { class. }\end{array}$ & 1 & 2 & 3 & 4 & 5 \\
\hline $\begin{array}{l}\text { 4. I am often unhappy with myself after } \\
\text { trying to address a group of people. }\end{array}$ & 1 & 2 & 3 & 4 & 5 \\
\hline $\begin{array}{l}\text { 5. Although I talk fluently with my } \\
\text { friends I am at a loss for words in } \\
\text { science class discussions. }\end{array}$ & 1 & 2 & 3 & 4 & 5 \\
\hline $\begin{array}{l}\text { 6. I am reluctant to say words aloud } \\
\text { that I can't pronounce well. }\end{array}$ & 1 & 2 & 3 & 4 & 5 \\
\hline
\end{tabular}

7. If you often speak in large group discussions in science class (asking a question, answering a question, sharing your homework solutions with the whole class, etc.), what influences your decision to speak? If you do not often speak to the whole science class, what stops you?

8. Identify and explain the ways that help you learn and remember the meaning of vocabulary the most and the least (you may include those used in this unit: 4-quadrant flashcards, letter writing, dictionary.com, group textbook reading, and/or review games).

9. How would/did learning and practicing how to pronounce scientific vocabulary words effect your participation in class discussions? Why? 
APPENDiX C: VOCABULARY TERMS

Unit 1 - Genetics (Group A - Treatment, Group B - Control)

\begin{tabular}{|l|l|}
\hline \multicolumn{1}{|c|}{ Lesson Vocabulary Activity } & \multicolumn{1}{|c|}{ Vocabulary Terms Taught and Applied } \\
\hline $\begin{array}{l}\text { An Introduction to } \\
\text { Linguistics and Vocabulary } \\
\text { Flashcards }\end{array}$ & Heterozygous, Homozygous, Gene, Allele, Gamete \\
\hline Read-Alouds & $\begin{array}{l}\text { Phenotype, Genotype, Dominant, Recessive, } \\
\text { Monohybrid Cross }\end{array}$ \\
\hline $\begin{array}{l}\text { Science Words and } \\
\text { Storytelling }\end{array}$ & $\begin{array}{l}\text { Law of Segregation, Law of Independent Assortment, } \\
\text { Parental Generation, F1 Generation }\end{array}$ \\
\hline $\begin{array}{l}\text { Terminology and } \\
\text { Technology }\end{array}$ & $\begin{array}{l}\text { Codominance, Polygenic, Sex Linkage, } \\
\text { Incomplete Dominance, Pedigree }\end{array}$ \\
\hline Reverse Jeopardy & No new words \\
\hline
\end{tabular}

Unit 1 - Evolution (Group A - Control, Group B - Treatment)

\begin{tabular}{|l|l|}
\hline \multicolumn{1}{|c|}{ Lesson Vocabulary Activity } & \multicolumn{1}{|c|}{ Vocabulary Terms Taught and Applied } \\
\hline $\begin{array}{l}\text { An Introduction to } \\
\text { Linguistics and Vocabulary } \\
\text { Flashcards }\end{array}$ & $\begin{array}{l}\text { Convergent, Divergent, Speciation, Pre-zygotic, } \\
\text { Post-zygotic }\end{array}$ \\
\hline Read-Alouds & $\begin{array}{l}\text { Homologous, Analogous, Vestigial, Hominid, } \\
\text { Bipedalism }\end{array}$ \\
\hline $\begin{array}{l}\text { Science Words and } \\
\text { Storytelling }\end{array}$ & $\begin{array}{l}\text { Prehensile, Primate, Sexual Selection, Carbon Dating, } \\
\text { Phylogenetic Tree }\end{array}$ \\
\hline $\begin{array}{l}\text { Terminology and } \\
\text { Technology }\end{array}$ & $\begin{array}{l}\text { Morphology, Gene Flow, Biogeography, } \\
\text { Emigration/Immigration, Coevolution }\end{array}$ \\
\hline Reverse Jeopardy & No new words \\
\hline
\end{tabular}




\section{P Portland State \\ UNIVERSITY}

June $7^{\text {th }}, 2012$

\section{Human Subjects Research Review Committee}

Proposal Application for Stacie Beck

\section{Project Title and Prospectus}

Deoxyribonucleic acid and other words students avoid speaking aloud: Evaluating the role of pronunciation on participation in secondary school science classroom conversations

Student's verbal participation in science classrooms is an essential element in building the skills necessary for proficiency in scientific literacy and discourse. The myriad of new, multisyllabic vocabulary terms introduced in one year of secondary school biology instruction can overwhelm students and further impede the self-efficacy needed for concise constructions of scientific explanations and arguments. Factors inhibiting students' inclination to answer questions, share ideas and respond to peers in biology classrooms include confidence and self-perceived competence in appropriately speaking the language of science. Providing students with explicit, engaging instruction in methods to develop vocabulary for use in expressing conclusions is critical for expanding comprehension of science concepts. The objective of this study is to answer the research question: Can the frequency and propensity of student participation in class discussion be increased by instruction in the pronunciation of scientific vocabulary? This study will fuse the recommended strategies for engaging vocabulary instruction with linguistic practices for teaching pronunciation to examine the relationship between a student's ability to pronounce challenging bio-terminology and their propensity to speak in teacher-led, guided classroom discussions. Interviews, surveys, and measurements quantifying and qualifying students' participation in class discussions before and after explicit instruction in pronunciation will be used to evaluate the potential of this strategy as an appropriate tool for increasing students' self-efficacy and willingness to engage in biology classroom conversations. Findings from this study can contribute to the current body of literature on best practices for instruction of scientific literacy skills, expressly the practices of oral communication as a function of scientific discourse. 


\section{Type of Review}

This research qualifies for an exemption of review, as it solely involves research on the effectiveness of instructional techniques in an established educational environment. Student confidentiality and anonymity will be prioritized and managed through password protected computer files and locked cabinet storage throughout the collection and analysis of all participation data, interviews, and surveys.

\section{Subject Recruitment}

This research will take place in two high school biology classes at Southridge High School in the Beaverton School District. Student participants will be in the $11^{\text {th }}$ grade with demographics representative of the greater Portland metro area. Intact classes with pre-assigned students will make up the study groups as opposed to a random assignment. These classes typically have a student population of approximately 45 students, giving a total sample size will be approximately 90 . All students in each classroom will be invited to participate in the research via personal correspondence (in-class) and letters to take home in early October, 2012. All students who return a signed Informed Parental Consent Form will be included in the study.

\section{First-Person Scenario}

Student X (female, 15yrs old: "At the beginning of the school year I took a letter home about a new research study about science education and my mom said I could participate. I didn't know what it was about and we didn't do anything different in class except answer questions on a survey about speaking up and using science vocabulary words aloud in class. We took that survey at the beginning and end of our genetics unit. Then Ms. Beck, the biology class student teacher, asked if she could interview me about pronouncing science vocabulary words and using them in class. I said yes and she came and got me from a study hall and brought me back to Mrs. Martin's classroom. There were six other students in the class who said they did interviews with Mrs. Beck too, but we didn't do it at the same time. We sat down across from each other at a lab table while Ms. Mayo sat at her main teacher desk. There was a microphone attached to the computer and Mrs. Beck explained that it was a software tool so that everything I said was translated right into text on the computer and she didn't have to record everything by hand. I thought that was pretty cool (she still took some notes by hand though). Then she asked me five questions about talking aloud in biology class and if learning to pronounce the words made a difference in how much I speak in class and use those words. I talked for a while about why I don't raise my hand to talk and how there are too many big words 
in science class. At the end of the interview I thought it was really neat that she cared about what I thought and I'm glad I participated."

\section{Potential Risks and Safeguards}

No anticipated risks to subjects are inherent in this study. Students will not be academically or socially penalized if they opt not to participate in this study and no physical, social, psychological, employment, legal, economic, risk of coercion, discomfort or embarrassment potential exists for those students who do opt to participate. Safeguards for risk prevention include anonymity and privacy of all student personal information in data collected regarding student participation and interview/survey responses.

\section{Potential Benefits}

All students will benefit from increases science classroom learning, regardless of their participation in this study. Those students participating in interviews will benefit from the opportunity to share their personal thoughts and opinions of the learning environment and teaching methods. Students participating in surveys will also have the benefit of selfassessing their learning styles and preferences. No academic or material rewards or compensation will be available to participants, including but not limited to grade increases or extra credit. The benefit of the study to the professional community of science educators includes an increase in knowledge about the role of teaching scientific vocabulary pronunciation skills in classroom participation.

\section{Confidentiality, Records \& Distribution}

Any information that is obtained in connection with this study and that can be linked to, or identify student participants will be kept confidential. This information will be kept confidential by replacing students' names with unique identification numbers in all reported data and results. Student participation forms and surveys that will be used in class will use student names during the data collection period only and pseudonyms will replace individual names in all subsequent reporting. Students will not have visual access to data collected during classroom activities and the data collector will be placed at the rear of the room. All information will be stored in a locked cabinet or password-protected electronic format during and after data collection. Interview recordings and transcripts, using voice-to-text software will also be maintained in a password-protected electronic format. Audio recordings will be necessary in this research to codify student perceived perceptions of the benefits of instruction in pronunciation. Pseudonyms will again be used in reporting of results. Secure transportation of records from the classroom to the researcher's home or campus will occur by using a locked briefcase holding all paper and 
computer-based information. Data and records shall be kept on file at the Portland State University Center for Science Education in a locked cabinet for a minimum of three years after the completion of research and will be destroyed through shredding of paper documents and permanent deletion of electronic files.

\section{Training and Experience}

This researcher is being trained through the PSU Graduate School of Education and Center for Science Education to work with secondary school students, assess them properly and employ the most current teaching strategies found in professional literature. I will be working with a veteran, cooperating teacher in the classroom in addition to being observed by a University Supervisor and advised by the PSU faculty on my advisory committee.

\section{Appendix A: Informed Parental Consent Form}

\section{Portland State \\ UNIVERSITY}

\section{Educational Research on Science Learning}

Your child is invited to participate in an educational research study conducted by Stacie Beck from Portland State University. The Beaverton School District has welcomed this research to gain a better understanding of science teaching and learning. In partnership with Portland State University, the Beaverton School District, and Southridge High School, the purpose of this study is to improve science instruction and provide an opportunity for an enriching experience for your child.

The researcher hopes to learn how a specific teaching method might influence students' understanding of science. This study is being conducted in partial fulfillment of the requirements for a Master's degree under the supervision of William Becker, Ph.D. Your child was selected as a possible participant in this study because of his/her enrollment in Brooke Mayo's biology class at Southridge High School.

All students enrolled in the class will participate in the same learning activities. This study will analyze student work collected during three weeks of instruction. By signing this consent form, you give permission for your child's work to be analyzed. Your child may also be asked to be interviewed by the researcher. Any information that is obtained in connection with this study and that can be linked to your child or identify your child 
will be kept confidential. This information will be kept confidential by replacing students' names with unique identification numbers. All information will be stored in a locked cabinet, or password-protected electronic format.

Your child's participation is voluntary. He/she does not have to take part in this study, and it will not affect his/her final grade or relationship with the teacher or with Portland State University. Also, you may withdraw your permission for your child to participate from this study at any time. Likewise, your child may withdraw his/her consent at any time.

If you have questions or concerns about your child's participation in this study, please contact Brooke Mayo at Southridge High School, 9625 SW $125^{\text {th }}$ St. Beaverton, OR 97008, phone \#503.259.5400. If you have concerns about your child's rights as a research subject, please contact Research and Strategic Partnerships, Market Center Building $6^{\text {th }}$ floor, Portland State University, (503) 725-4288.

Thank you for considering this request.

Sincerely yours,

Stacie Beck

Please keep this page for your records. 


\section{Consent Form}

Please sign this page and return it to Ms. Mayo.

Your signature indicates that you have read and understand the above information and agree to let your child's work be analyzed as part of this study. Your child will participate in classroom activities regardless of the inclusion of their work in the study. The researcher will provide you with a copy of this form for your own records.

Child's Name

Biology period: $3^{\text {rd }}$ or $5^{\text {th }}$ (circle one)

Signature of Parent/Guardian

Date

Print name of Parent/Guardian 


\section{Portland State University HSRRC Memorandum}

To: $\quad$ Stacie Beck

From: HSRRC 2012

Date: June 13, 2012

Re: HSRRC exempt review of your application titled, "Deoxyribonucleic acid and other words students avoid speaking aloud: Evaluating the role of pronunciation on participation in secondary school science classroom conversations" (HSRRC Proposal \#122206)

Your proposal is exempt from further Human Subjects Research Review Committee review, and you may proceed with the study.

Even with the exemption above, it was necessary by University policy for you to notify this Committee of the proposed research, and we appreciate your timely attention to this matter. If you make changes in the research protocol, the Committee must be notified in writing, and changes must be approved before being implemented.

If you have questions or concerns, please contact the HSRRC at 503-725-2243 or visit us at Research and Strategic Partnerships, Market Center Building, $6{ }^{\text {th }}$ Floor.

Exempt memo 